\title{
Lázaro Díaz del Valle y de la Puerta. Datos documentales para su biografía ${ }^{1}$
}

\author{
José María Riello Velasco \\ Universidad Complutense de Madrid
}

\begin{abstract}
RESUMEN. Datos documentales sobre la vida y la muerte de Lázaro Díaz del Valle, autor del Origen E Yllustracion del nobilissimo y Real Arte de la Pintura y Dibuxo, obra fundamental en el panorama de la literatura artística española del siglo XVII.

Palabras clave: Lázaro Díaz del Valle, literatura artística, León, Santa María de Carbajal, Antonio Arias, Juan Antonio Escalante, siglo XVII.

ABSTRACT. Documents about the live and the death of Lazaro Díaz del Valle, author of Origen E Yllustracion del nobilissimo y Real Arte de la Pintura y Dibuxo, a fundamentaly work on the spanish artistic literature of XVIIth century.

Key Words: Lázaro Díaz del Valle, artistic literature, León, Santa María de Carbajal, Antonio Arias, Juan Antonio Escalante, XVIIth century.
\end{abstract}

En muy temprana fecha, a finales del siglo XIX, Juan López Castrillón pretendía hacer justicia con un ilustre leonés olvidado por la historiografía a pesar de haber puesto su pluma, en palabras de este autor, al servicio del "engrandecimiento $y$ esplendor de la patria", con numerosas obras de genealogía e historia: Lázaro Díaz del Valle y de la Puerta ${ }^{2}$. Dentro de ese cuan-

\footnotetext{
${ }^{1}$ Este trabajo se inscribe en el marco del Proyecto de Investigación I+D (Ministerio de Ciencia y Tecnología), Ref.: BHA 2000-0711: “Fuentes literarias y figurativas del siglo XVII español: arquitectura y perspectiva", y forma parte de un análisis más amplio que constituirá nuestra tesis doctoral en elaboración: “Un caso singular de la literatura artística española del siglo XVII: Lázaro Díaz del Valle".

${ }^{2}$ López Castrillón no sólo fue pionero en lo que se refiere a la biografía de Lázaro Díaz del Valle, sino que
}

tioso elenco de obras que había dejado escritas y que nunca llegaron a la imprenta, Díaz del Valle escribió una importante obra para la historia del arte de nuestro país: el Origen E Yllustracion del nobilissimo y Real Arte de la Pintura y Dibuxo, elaborado entre 1656 y 1659 en su mayor parte, pero prolongado en sus últimas anotaciones hasta, al menos, 1662, manuscrito que hoy se conserva en la biblioteca del Instituto Diego Velázquez, integrado en el Consejo Superior de Investigaciones Científicas de Ma$\mathrm{drid}^{3}$. Con ese manuscrito, Díaz del Valle

reseñó las obras que éste había dejado escritas y que, hasta entonces, se conocían. Vid. J. LóPEZ CASTRILlón, "Don Lázaro Díaz del Valle y de la Puerta", en Boletín de la Real Academia de la Historia, XII, 1888, pp. 471-479. 
inauguraba en España el género biográfico artístico, entendiendo por tal una sistematización de vidas de artistas españoles y extranjeros, pues es sabido que algunos de sus precedentes en estas lides habían intercalado excursos biográficos en sus tratados, incluso tendenciosamente, como el caso flagrante de Francisco Pacheco, que añadió en El Arte de la Pintura la biografía de su yerno, Diego Velázquez.

La importancia del manuscrito no sólo viene dada por su carácter inaugural. Creemos que puede ser considerado como el cabal refrendo de una década excelsa en la producción artística española, pues baste señalar que, en esos años, alcanza su plenitud el mecenazgo de Felipe IV y es, acaso, el periodo de mayor esplendor de Velázquez y Alonso Cano, tanto como la confirmación de Antonio de Pereda en el género de las Vanitas, particularmente querido en el mundo hispánico -y a pesar de que el, quizá, más precioso lienzo de Pereda sobre este asunto esté fechado c. $1634^{4}$-, artistas cuyas biografías fueron glosadas con amplitud por Díaz del Valle. Además, buena parte de la trascendencia de la obra está en el uso, y abuso, que Antonio Palomino hizo de él en lo que podemos entender como el gran colofón de la tratadística española del siglo XVII: el Museo Pictórico y Escala Óptica, éste sí publicado entre 1715 y 1724 . Nos referimos, claro está, al tomo III, el Parnaso Español Pintoresco y Laureado, en el que a pesar de que se afirma, en afortunado pero descarado símil escultórico, que "como [Díaz del Valle] no era de la profesión", y fuera "menester fundir" el manuscrito "para [después] vaciarlo" ${ }^{\prime \prime}$, éste constituyó buena parte de la savia de las biografías que escribió el

4 Alegoría de la Vanidad. Kunsthistorisches Museum, Viena. GG Inv. № 711.

${ }^{5}$ A. Palomino, El Museo Pictórico y Escala Óptica III: El parnaso español pintoresco laureado, Madrid, 1988, p. 25.
}

pintor cordobés, edulcoradas por su pluma profesional. Por último, Díaz del Valle contribuía, como otros tantos no profesionales de la pintura -entre los que cabría destacar abogados, como Juan de Butrón; literatos, como Lope de Vega o Calderón de la Barca; y clérigos, como fray José de Sigüenza o fray Francisco de los Santos-, a un debate fundamental del siglo XVII en España: la liberalidad del arte de la pintura, pues en su obra Díaz del Valle recogía, entre otras cosas, las honras y mercedes que reyes y emperadores habían concedido a los pintores a lo largo de la historia.

A pesar de la importancia, creemos que probada, del manuscrito, los únicos historiadores que consideraron de relevancia aportar datos biográficos de Díaz del Valle fueron López Castrillón y Francisco Javier Sánchez Cantón ${ }^{6}$, y en estos casos, de forma parcial, pues transcribieron extractos de los documentos que habían hallado, relativos sobre todo al expediente personal de Palacio y al testamento. Aunque López Castrillón conoció la partida de bautismo y los documentos recogidos en el Libro de Autos (que él llama "de Acuerdos") del Convento de Santa María de Carbajal de León, no los transcribió completamente, limitándose a referir su existencia ${ }^{7}$. En el siglo $\mathrm{XX}$, los historiadores del arte español se remitieron, para los datos biográficos, al excelente trabajo de López Castrillón, como nosotros mismos hicimos en otro lugar ${ }^{8}$.

${ }^{6}$ F. J. SÁNChez CANTÓN, Fuentes literarias para la historia del arte español, Madrid, 1933, v. II, pp. 321-393.

${ }^{7}$ Con respecto a la historia del convento, con un pequeño epígrafe dedicado a Díaz del Valle (pp. 335338), puede verse G. M. Colombás, San Pelayo de León y Santa María de Carbajal. Biografía de una comunidad femenina, León, 1982. Por ser ésta la historia oficial del convento, seguimos al autor en cuanto a la ortografía de la advocación (Carbajal en lugar de Carvajal).

8 J. Ma Riello VelasCO, “Tres manuscritos de Lázaro Díaz del Valle y una nueva interpretación de sus 
Siguiendo las pistas que daba éste en su artículo, tuvimos la fortuna de encontrar noticias documentales sobre la vida y la muerte de Díaz del Valle, y creemos que es el momento oportuno -con nuestra tesis doctoral en marcha- para darlas a conocer en toda su amplitud aunque, en algunos casos, hayamos optado por transcribir las partes esenciales y significativas de los documentos por no ahondar en la repetición y no reiterar fórmulas legales conocidas, tal y como advertimos al inicio del Apéndice Documental. Junto con las noticias legadas por López Castrillón y Sáchez Cantón, hemos construido la biografía de Díaz del Valle, a la espera de nuevas aportaciones documentales, pues grande vacío hay de sus años en la Corte.

Hijo legítimo de Bartolomé del Valle y María de la Puerta, Lázaro Díaz del Valle y de la Puerta debió nacer entre los últimos días del mes de marzo y los primeros del mes de abril de 1606, pues fue bautizado por el maestro Rojas Serrano, rector de la parroquia de San Martín de León, el día 3 de abril, en esa misma iglesia, cuyo ábside central forma parte de uno de los lados mayores de la Plaza Mayor de la ciudad leonina9. López Castrillón sospecha que "la familia de D. Lázaro era de las que constituían la primera nobleza de la ciudad", por el tratamiento de Doña que se da a su madre y hermanas, el matrimonio de su sobrina con "persona de distinción" y la pertenencia de su padre y un primo -Melchor del Valle (el Sordo)- a la cofradía del Pendón de San

escritos sobre pintura", Goya, 298, enero-febrero 2004, pp. 37-44.

${ }^{9}$ Vid. Apéndice Documental, doc. I. Tuvo Lázaro tres hermanas: Melchora; Jacinta, monja del convento de Santa María de Carbajal de León, institución a la que estuvo ligado nuestro personaje por otras circunstancias que veremos; y Paula, cuya hija del mismo nombre se casó con Fernando de Olivera Madrid y Santistevan, señor del mayorazgo de Quintana de Raneros.
Isidoro, "entre cuyos estatutos es el primero el de Nobleza" $a^{10}$.

De su primera juventud y su formación nada sabemos, más que lo que deduzcamos de su obra escrita posterior y su actividad como cantor en la Capilla Real, de la que llegó a ser maestro según se averigua por el Libro de Autos del convento de monjas benedictinas de Santa María de Carbajal, del cual fue bienhechor ${ }^{11}$; en dicho Libro también se le llama "licenciado", para la época casi sinónimo de clérigo, y ello lo confirman unas líneas que Gerardo Ernesto de Franckenau le dedica en su Biblioteca Hispánica, en que se refiere a él como "capellán de altar" de las Descalzas Reales de Madrid $^{12}$. A la Corte acudiría, hacia 1622 ó 1623 según se desprende de su expediente personal en Palacio -en documentos de 11 de marzo de $1638^{13}$ y de 8 de febrero de $1639^{14}$ refiere Díaz del Valle "que â 16 anos [sic, años] que sirue" en la Real Capilla-, en busca de insigne trabajo y quizá espoleado por la presencia en la misma de dos de sus tíos, uno de ellos, Cristóbal Gómez de la regii Matritensis, scripsit.", en "GERHARDI ERNESTI / de FRANCKENAU, / Equit. Danic. / BIBLIOTHECA / HISPANICA / HISTORICO-GENEALO- / GICOHERALDICA. / LIPSIAE, / SumptibuS MAUR. GEORGII WEIDMANNI, / SAC. REG. POL. MAJ. AC ELECT. SAXON. / BIBLIOPOLAE. ANNO M DCC XXIV. [1724]", p. 279.

Francisco J. Sánchez Cantón apunta que el propio Díaz del Valle se llama, en alguna de sus obras, “capellán de Carlos II". De ser así, en todo caso, sería capellán en el periodo de regencia de Mariana de Austria y durante la minoría de edad de El Hechizado, pues nuestro personaje murió en 1669 y el rey no alcanzó la mayoría hasta 1675. Vid. F. J. SÁNCHEZ CANTÓN, op. cit., p. 325.

13 Vid. Apéndice Documental, doc. II. b.

${ }^{14}$ Ibidem, doc. II. c.
} 
Puerta, ujier de saleta ${ }^{15}$; y el otro, Francisco Gómez de Olivera, "contador de resultas y pagador de los consejos". A su actividad en la Real Capilla y a su calidad de "caponcillo" entró en ella como "cantorcico" el 25 de diciembre de $1633^{16}$ - dedica Jerónimo de Barrionuevo un mordaz comentario en sus celebérrimos Avisos:

"A un músico capón del Rey, que se llama don Lázaro del Valle, le han retoñado los genitales, y está tan gozoso que los enseña a todos. Lo que es por curiosidad no puedo dejar de verlos, cosa de que los capones todos están muy gozosos, no perdiendo ninguno las esperanzas de verse algún día hombre hecho y derecho"17.

15 Según los documentos encontrados, Cristóbal Gómez de la Puerta fue sumiller de la cava de la reina de Francia, Ana de Austria, desde el 17 de octubre de 1615 y durante 22 meses. A su vuelta a España fue nombrado ujier de saleta el 7 de julio de 1617. El sumiller de la cava debía ser el responsable de la dependencia donde se guardaban el agua y el vino que bebía la familia real y, por tanto, persona de completa confianza de los reyes, lo que pudo contribuir en la pronta incorporación de Díaz del Valle a la Corte.

Ana de Austria (Valladolid, 1601-París, 1666), hija de Felipe III y de Margarita de Austria, se casó en 1615 con Luis XIII de Francia; Cristóbal Gómez de la Puerta viajó con la nueva reina al país vecino. López Castrillón confundió a Ana con María Teresa de Austria (1638-1683), hija de Felipe IV; vid. J. LÓPEZ CASTRILLÓN, Art. cit., p. 473.

16 Vid. Apéndice Documental, docs. II.a y III.

${ }^{17}$ El aviso es del día 26 de junio de 1655; vid. J. de BARRIONUEVO, Avisos (1654-1658), Edición y estudio preliminar por A. Paz y Melia, Madrid, 1968, vol. I, p. 154. Ya fue recogido por Francisco Asenjo Barbieri en sus Papeles, conservados en la Biblioteca Nacional de Madrid (Ms. 1402768-69), junto a otro cuya referencia a Díaz del Valle es más dudosa, por la procedencia gallega de los músicos: "Tres músicos de la capilla real, dos tiples caponcillos, el uno Lázaro y el otro Bartolomé, los mejores que había, naturales de Galicia, y un tenor que habían traído de Cuenca, se han ido a Portugal. Faltan desde el lunes 11 de éste, llamados del Rebelde a instancia de don Felipe de la Cruz, que, como avisé, se fue allá"; vid. J. de BARRIONUEVO, Op. cit., vol. I, p. 206; y F. ASENJO BARBIERI, Biografías y documentos sobre Música y Músicos Españoles (legado Barbieri). Volumen 1. Edición, trans-
Díaz del Valle elevó dos memoriales al Bureo pidiendo raciones y otros gajes como único heredero que era de su tío Cristóbal Gómez de la Puerta, en las fechas citadas anteriormente de 1638 y 1639, que no le fueron concedidos ${ }^{18}$ : "el Bureo es de parecer que porque la despensa esta cargada podia V M[a]g[esta]d seruirse de encomendarle al consejo de camara". El día 1 de enero de 1641 se le hizo merced de una plaza ordinaria por aumento ${ }^{19}$; y en 25 de mayo de 1646 el Bureo le concedió "una pension eclesiastica de ciento y cinquenta ducados por ser su profesion el hir [sic, ir] por la Yglesia"20.

No se limitó Lázaro a su actividad musical y, en palabras de López Castrillón, "las Cortes de Castilla y de León (...) proveyeron en D. Lázaro el cargo de cronista general de estos reinos" ${ }^{21}$. Él mismo, en sus obras y otros documentos, se declara "Coronista general", y Sánchez Cantón asegura que así consta en los Libros de Cortes de $1655^{22}$. De su labor como tal conservamos buenos y laudatorios testimonios de otros eruditos en la materia; de hecho, de sus obras hicieron uso otros genealogistas como Luis de Salazar y Castro, de las que dice están "escritas con exactitud e inspiradas en el amor a la verdad"23, o fray José de Manzano, en su Vida y

-

cripción e introducción de Emilio Casares, Madrid, 1986, p. 176. También cita el primer aviso F. CALVO SERRALLER, Teoría de la pintura del Siglo de Oro, Madrid, 1999, pp. 461-462, nota 4.

Para la especial figura del capón y una nueva valoración de su importancia en España y el papel de nuestro país en la creación de tan destacada modalidad, vid. A. MEDINA, Los atributos del capón. Imagen histórica de los cantores castrados en España, Madrid, 2001.

18 Vid. Apéndice Documental, docs. II. b y II. c.

19 Ibidem, doc. III.

${ }^{20}$ Ibidem, doc. II. c.

${ }^{21}$ Citado en J. López CASTRILlón, Art. cit., p. 474.

22 F. J. SÁNCHEZ CANTÓN, Op. cit., p. 325.

23 J. López CASTRILlón, Art. cit., p. 474. 
portentosos milagros del glorioso San Isidoro ${ }^{24}$. Otros egregios escritores lo llaman "decente poeta", así Gaspar Melchor de Jovellanos en

-

24 “VIDA, / Y PORTENTOSOS MILAGROS / DE EL GLORIOSO / SAN ISIDORO, / ARZOBISPO DE SEVILLA, / Y EGREGIO DOCTOR, / Y MAESTRO DE LAS ESPAÑAS, / CON UNA BREVE DESCRIPCION / de su magnifico Templo, y Real Casa de el mismo señor S. Isidro [sic, Isidoro], / en la muy Noble Ciudad de Leon: / ESCRITA / POR EL R. P. M. FRAY JOSEPH MANZANO, I de el Sagrado Orden de Predicadores, Hijo de el Ilustre Convento / de San Estevan de Salamanca, y Calificador de la Suprema. / SACALA A LUZ / EL REAL CONVENTO DE SAN ISIDRO [sic, Isidoro] DE LEON, / Y LA CONSAGRA / AL MONARCHA DE DOS MUNDOS, / EL CATHOLICO REY DE LAS ESPAÑAS, / NUESTRO SEÑOR / DON PHELIPE QUINTO, / (QUE DIOS GUARDE) / CON LICENCIA: / EN SALAMANCA, EN LA IMPRENTA REAL, / Por Eugenio Garcia de Honorato y San Miguel. / Año de 1732.”, pp. 358-359: “(...) Esta Genealogia de el Gran Patriarcha Santo Domingo, la hemos derivado de el citado Author Don Lazaro Diaz de el Valle, Choronista General de los Reynos de Castilla, y de Leon, por ellos juntos en Cortes, en el reynado de el Catholico Rey de España, el Señor Don Felipe Quarto: que de la Historia que escribiò de los Reyes de Leon, y de Castilla, y de las ilustres Casas, que enoblecen [sic, ennoblecen] esta Monarchia, en la Corte de Madrid, sacò en vitèla dos volumenes grandes, con sus Arboles Genealogicos, que formò de las oculares noticias que adquiriò de varios archivos, y que le subministraron los Escritores de mas fe, assi Españoles, como Estrangeros.

Para el original de estos libros en esta Ciudad de Salamanca, partido (no sabemos por què accidente) entre dos Dueños, que cada uno reserva su parte con la mayor estimacion. la primera, la tiene Don Luis de Paz y Nieto y Silva, sugeto de conocida calidad. la segunda, la possee Doña Maria de los Remedios, esposa que fue de Don Domingo de Guzman, Cavallero ilustre de la nobilissima Casa de los Señores Marqueses de Almarza: hazese cargo este diligentissimo Choronista, de lo que otros Authores graves escribieron, à cerca de la esclarecida prosapia de los Guzmanes, que les dàn por tronco Principe Estrangero, y no Español; y para explicar enteramente su dictamen, y concepto, pone los siguientes versos:

Gurbàn vuelvete à Bretaña,

que el renombre de Guzman

no es Bretòn, ni es Alemàn,

que es hijo de nuestra España.

$Y$ no ha de tener enmienda

que la Infanta Hermenessenda

con Gundemaro casò

y el Guzmàn se derivò,

de que gozò mas hazienda". carta a Juan Agustín Ceán Bermúdez ${ }^{25}$; y este mismo, "muy buen dibujante" 26 .

Curiosa es la noticia que Díaz del Valle registra en una de sus obras, la Ilustración genealógica de D. Alonso Pérez de Guzmán el Bueno, patriarca de las Indias, pues dice que fue paje del Patriarca de las Indias Don Diego de Guzmán y después familiar o criado de Don Alonso Pérez de Guzmán el Bueno $^{27}$.

${ }^{25}$ La carta fue publicada en primer lugar por Cándido Nocedal, que tenía a la vista el autógrafo de Jovellanos, en poder de Valentín de Carderera; vid. G. M. de JOvellanos, Obras: publicadas e inéditas. Colección hecha por Cándido Nocedal. Madrid, 1859, vol. II, pp. 361-362. Ese manuscrito lo vio Xavier de Salas y, transcribiéndolo, lo publicó en parte; vid. X. de SALAS, "Dos cartas de Jovellanos", Archivo Español de Arte, IX, 1933, pp. 65-67. Probablemente la edición más accesible sea G. M. de JovellanOS, Obras completas. Tomo III. Correspondencia. 2o. (Julio 1794-Marzo 1801). Edición crítica, introducción y notas de José Miguel Caso González, Oviedo, 1986, pp. 129-132.

26 “DICCIONARIO HISTÓRICO/ DE LOS MÁS ILUSTRES PROFESORES/ DE LAS BELLAS ARTES/ EN ESPAÑA. COMPUESTO POR/ D. JUAN AGUSTIN CEAN BERMUDEZ/ Y PUBLICADO POR/ LA REAL ACADEMIA DE S. FERNANDO/. MADRID EN LA IMPRENTA/ DE LA VIUDA DE IBARRA. AÑO DE 1800". Ed. Facsímil: Valencia, 1992, vol. I, p. IX, n. 3: "Este escritor fue cronista de los reynos de Leon y Castilla, y de muy extendidos conocimientos, según el gusto de su tiempo: muy buen dibuxante, pues se conservan de su mano un correcto dibuxo á la pluma del rey D. Pelayo, muchos y buenos escudos de armas y adornos, que hacia para sus empresas y árboles genealógicos: decente poeta, pues componia sonetos en loor de los artistas; $y$ amigo de los que vivian entónces en el reyno".

${ }^{27}$ El título completo de esta obra es "Ilustracion genealogica de el muy illustre y excelentissimo Sr. Don Alonso Perez de Guzman el Bueno, Patriarcha de las Indias, Arzobispo de Tyro, Mayor capellan y Limosnero del muy catolico Rey de las Españas y Emperador de América, D. Felipe IIII [sic, IV) el Grande, N. Señor. Compuesta por D. Lázaro Diaz del Valle y de la Puerta, natural de la ciudad de Leon, que humil[de]mente se la ofrece, dedica y consagra a su S. Illma. con un catálogo de todos los Sres. Patriarchas de las Indias que ha auido; con el origen desta Dignidad Patriarchal; $y$ de los Señores Capellanes mayores que han tenido los catholicos señores Reyes de España; y del nombre de Capellan y de Capilla. Año del Señor 1656. Y un índice de los Sumilleres de cortina con las genealogías de los Cape- 
En fin, hombre de amplias miras e inquietudes, otorgó testamento en Madrid, a 26 de febrero de 1669, tan enfermo que no pudo firmar, ante el escribano real Juan de Siles Calahorra ${ }^{28}$. Murió al día siguiente, el 27 de febrero, en casa de Catalina de Ulloa, sita en la calle Silva ${ }^{29}$. Tras ser depositado ese mismo día, por disposición testamentaria, en el convento de Santa María de los Ángeles de la Corte $^{30}$, sus huesos fueron trasladados después (entre el 7 de junio y el 14 de agosto de $1670^{31}$ ), tal y como él quiso,

llanes de honor y Predicadores de su Mág. que en tiempo de su Illma. han tomado posesión."; vid. C. FERNÁNDEZDURO, "Noticias acerca del origen y sucesión del patriarcado de las indias occidentales", Boletín de la Real Academia de la Historia, VII, 1885, pp. 198-216; J. LÓPEZ CASTRILLÓN, Art. cit., pp. 473-474.

También la conoció Franckenau, pero la llamó de otra forma, como ya denunció López Castrillón (Art. cit., p. 477); vid. "GERHARDI ERNESTI / de FRANCKENAU, / Equit. Danic. / BIBLIOTHECA / HISPANICA / HISTORICO-GENEALO- / GICOHERALDICA. / LIPSIAE, / SumptibuS MAUR. GEORGII WEIDMANNI, / SAC. REG. POL. MAJ. AC ELECT. SAXON. / BIBLIOPOLAE. ANNO M DCC XXIV », p. 279: "TRATADO de la Capilla Real de los Sennores Reyes de Espanna; sive de Sacello Regio librum, ciu inseruit stemmata plurium (ut qui Sacello isti supremo honore praesse solent) Indiarum Patriarcharum, itemque Capellanorum honorariorum \& Concionatorum Regiorum, imprimis fusius pertractat stemma Guzmannicum, cui Alphonsus Perez de Guzman, qui eo tempore Indiarum Patriarcha cluebat, cuique liber iste nuncupatus ab auctore fuerat, ortum suum debebat. Authenticum operis exemplar postea in suis asservavit scriuiis Don Petrus Portocarrero, Indiarum itidem Patriarcha; laudatque utrumque opus ut in rebus Genealogicis exacte $\mathcal{E}$ cum veritatis studio conscriptum Ludovicus de Salazar \& Castro ( $\sigma)^{\prime \prime}$.

28 Vid. Apéndice Documental, doc. IV. Sánchez Cantón confundió el nombre del escribano; no fue Francisco de Siles, sino Juan de Siles Calahorra. Vid. F. J. SÁNCHEZ CANTÓN, Op. cit., p. 326.

${ }^{29}$ Vid. Apéndice Documental, doc. V.

${ }^{30}$ Ibidem, doc. VI.

${ }^{31}$ El 7 de junio de 1670, Francisco Lobera, testamentario de Díaz del Valle, cobró de Juan Díaz Rodero, otro de los testamentarios, 22000 reales para entregarlos al convento de carbajalas y para el traslado del cadáver; el 14 de agosto del mismo año, Lobera ya estaba de vuelta en Madrid, donde cobró 2200 reales de parte de Díaz Rodero y José Hidalgo, el tercero de los testamentarios, por el viaje a León y la colocación al ya citado cenobio de monjas carbajalas de León, para ser allí enterrado en lugar decente $^{32}$, cerca de la reja del coro, con lápida cuyo texto él mismo se ocupó de dictar al escribano en el testamento:

"Aquí yace D. Lázaro Díaz del Valle y de la Puerta, natural desta ciudad de León, y criado del rey nuestro señor Felipe IV en su real Capilla, y su coronista general en estos reinos de España, el qual por grande devoción que tuvo á nuestro padre San Benito y á este santo convento se mandó trasladar á él desde el real de los Ángeles de Madrid, donde fue depositado en... y aquí fue sepultado en... Dejó una memoria de una misa perpetua cada día, que se ha de decir en este santo convento á las doce dadas. Rueguen á Dios por él ${ }^{\prime \prime 33}$.

Del testamento destaca, además del epitafio, el legado que Díaz del Valle hizo a su ciudad natal de "Dos libros que tengo escritos en pergamino y otro que es tercera parte que esta empezado de la historia de la nobleza del Reyno de Leon y Principado de Asturias". Se refería sin duda a la obra que Díaz del Valle consideraba como la mejor entre las suyas, Historia y Nobleza del Reino de León y Principado de Asturias ${ }^{34}$. Del

del epitafio. Vid. Apéndice Documental, docs. XIV y XV.

${ }^{32}$ Las obras del nicho costaron, finalmente, la nada despreciable cantidad de 600 ducados. Vid. Apéndice Documental, doc. XII.

${ }^{33}$ Vid. Apéndice Documental, doc. IV.

${ }^{34}$ Para una descripción más completa de la obra, vid. J. SOMOZA Y MONTSORIU, Catálogo de manuscritos e impresos notables del Instituto de Jovellanos de Gijón. Oviedo, 1883, pp. 72-74. Escrita entre 1657 y 1669 e inacabada, ha pasado por ser su obra más ambiciosa. Se divide en tres partes. La primera, con 229 folios, contiene "un mapa, árboles genealógicos, retratos, empresas y escudos de armas"; vid. J. LÓPEZ CASTRILLÓN, Art. cit., p. 476; fue de Luis de Paz Nieto y Silva, de Salamanca, y la vendió al colegio mayor de San Bartolomé de la misma ciudad; su último poseedor fue Jovellanos, que con su adquisición engrosó la librería que hoy conforma la Biblioteca Jovellanos de Gijón. La segunda parte, 
otro libro que cita en el testamento, "con iluminaciones que se intitula nobleza en sangre y heroicas Virtudes del Rey n[uest]ro s[eño]r Phelipe quarto" nada se sabe.

Al convento de Santa María la Real de Carbajal donó "Vna Ymagen que tengo de bulto de $n$ [uest] ra s[eño] ra de la Concep[ci]on con su peana dorada y Angeles"; la escultura fue vendida por 500 reales para afrontar algunas deudas, y por haber en el convento otra imagen "de mucha debozion". Y, lo importante para nosotros, dos cuadros que, suyos, donó a dicho convento: una Piedad de Antonio Arias ${ }^{35}$ que tenía en su casa,

que fue de doña María de los Remedios y, después, de Don Juan de Guzmán, hijo del marqués de Almarza, se encuentra en paradero desconocido. Estas noticias fueron recogidas por fray José de Manzano (vid. supra, nota 24). El tercer volumen, que López Castrillón no conoció más que por la cláusula del testamento de Díaz del Valle, en que lo donaba a su ciudad natal, lo encontró Sánchez Cantón en la biblioteca del British Museum (signatura Eg 1878) y allí lo revisó, destacando la parte contemporánea al autor "por las noticias directas que consigna". De la parte dedicada a Felipe IV hay fotocopia antigua y poco manejable en el Instituto Valencia de Don Juan de Madrid, donde nosotros la hemos podido estudiar, entre otras cosas por el hermoso obituario que el autor dedicó a su amigo Velázquez:

"Viernes, à las 3. de la tarde, 6 de Agosto, deste mésmo año [1660] murio en Madrid, Diego de Silua, y Velazquez, Pintor de camara del Rey N. S[eño] $r$ y su Ayuda de camara y Aposentador de Palacio, aqui en [sic, a quien] su Mag[esta]d queria bien, assí, por superior en el Arte de la Pintura, como por otras buenas partes, conq[ue] hauía seruidole, por todo lo qual Su Mag[esta]d le honrrò con El Ávito del orden militar de la cauallería de Sant Iago, conq[ue] este Grande Artifize honrrò su pecho, y tuuo el premio que merecio por su Virtud y serbicios q[ue] por muchos años, hizo a su Mag[esta]d: Fue insigne varon, en la pintura, y singular en hazer Retratos: Yaze en la Bobeda de la Parroquia de S. Iu[an] desta Villa de Madrid. Yo, perdî en el, vn buen amigo, porque correspondia à mî Voluntad" (fol. 175v).

35 Jovellanos conoció este lienzo, "con una cortina de gasa por delante", y en carta del 3 de octubre de 1795 lo dio a conocer a Ceán, que lo cita en su Diccionario histórico. Vid. G. M. de JOVEllanOS, Obras completas. Tomo III, op. cit., p. 152; Idem: Obras completas. Tomo VII. Diario, 2․ Cuadernos V, conclusión, VI y VII (desde el 1 de según dice en el testamento; y una Resurrección de Lázaro de Juan Antonio Escalante, que el pintor no tenía acabada cuando Díaz del Valle testó; ambas demuestran, una vez más, su gusto por la pintura.

Quisieron la desidia y los avatares del tiempo que la lápida se perdiera y hoy no se conserve. $\mathrm{Y}$ los cuadros, tras la restauración de la iglesia del convento, se encuentran, el de Arias, en una nueva capilla a la cual se accede por unas escaleras bajo las cuales se ha reubicado el cadáver de Díaz del Valle; y el de Escalante, sobre la puerta a los pies de la iglesia, necesitado de urgente restauración.

Adjuntamos también en el Apéndice Documental otros documentos sobre el cumplimiento de las disposiciones testamentarias de Lázaro Díaz del Valle relativas al cobro de gajes por su servicio en la Real Capilla, al menos hasta el 9 de febrero de 1674; y a la fundación de una memoria de misas para el Hospital de la Buena Dicha de Madrid, del 19 de agosto de $1670^{36}$. setiembre de 1794 hasta el 18 de agosto de 1797). Edición crítica, prólogo y notas de María Teresa Caso Machicado y Javier González Santos, Oviedo, 1999, p. 377; J. A. CEÁN BERMÚDEZ, Op. cit., vol. I, p. 71.

Para el cuadro de Arias, firmado y fechado en 1658, que "quizá pueda reputarse como su obra maestra" según Gómez-Moreno, vid. M. GÓMEZ-MORENO, Catálogo monumental de la provincia de León. Ed. facsímil: León, 1979, p. 307; J. URREA, “La pintura del siglo XVII en León", Tierras de León, 29, 1977; y D. ANGULO IÑ̃íGUEZ, A. E. PÉREZ SÁNCHEZ, Historia de la pintura española. Pintura madrileña del segundo tercio del siglo XVII, Madrid, 1983, pp. 19 y 29 (cat. 59) y lam. 10.

36 Vid. Apéndice Documental, doc. XVI. 


\section{APÉNDICE DOCUMENTAL}

Se han ordenado los documentos por estricto orden cronológico. En cuanto a los criterios de transcripción, se han seguido dos líneas básicas: la fidelidad a los originales y la comodidad del lector actual. En este sentido, no se han añadido tildes y las únicas añadiduras por nuestra parte han sido la separación de las palabras y el desarrollo de las numerosas abreviaturas. Lo que se ha añadido se especifica siempre entre corchetes: [...]. Los paréntesis, siempre que aparecen, son originales del documento respectivo. Se han obviado, por otra parte, las conocidas fórmulas legales, sustituidas por [...]. En cambio, se han añadido en nota a pie de página las definiciones que el Diccionario de la Real Academia Española de la Lengua da a palabras olvidadas o de escaso uso; y algunas aclaraciones sobre determinados documentos, señaladas en nota a pie de página con uno o varios asteriscos.

\section{Abreviaturas}

AGP Archivo General de Palacio

AHDM Archivo Histórico Diocesano de Madrid

AHPM Archivo Histórico de Protocolos de Madrid

ASMC Archivo de Santa María de Carbajal de León

ASML Archivo de la parroquia de San Martín de León

BN Biblioteca Nacional (Madrid)

D.R.A.E.L. Diccionario de la Real Academia Española de la Lengua

Esno. Escribano

fol. Folio

fols. Folios
Prot. Protocolo

s. d. Sin data

I) ASML: Libro $2^{\circ}$ de Bautizos, fol. 229: Partida de bautismo de Lázaro Díaz del Valle, 3 de abril de 1606.

en tres de abril de seiscientos y seis anos [sic, años] yo el $\mathrm{m}$ [aestr]o Rojas serrano R[ect]or de s[eño]r St Martin baptice un niño q[ue] se llamo lazaro hijo de bartolome de Valle y doña maria de la puerta fueron sus padrinos Ju[an] de Villafañe y doña ana flores testigos fr[ancis]co barela y leandro del castillo y Ju[an] de quintano yo iui supra FL M[aestr]o Rojas serrano R[ect]or [rubricado]

Al margen: lazaro de Valle

II) AGP, Expedientes Personales, $\mathrm{C}^{\underline{a}}$ 1064/27: Expediente Personal de Lázaro Díaz del Valle ${ }^{37}$.

II. a) Valle, Lázaro del. Cantorcico, fue recibido por Cantór en 25 de diciembre de 1633. En $1^{\circ}$ de enero de 1641, se le hizo merced de una plaza ordinaria por aumento. V. Martinez, Agustín.

II. b) Bureo ${ }^{38}$ de la R[ein]a N. S[eñor]a A 11 de marzo de 1638= no 21.

Refiere la pretension que don laçaro del Valle tiene de la rracion que vaco por cristoual Gomez de la Puerta su tio y de Vna pinsion y es de pareçer que puede $\mathrm{V}$ Mag[esta]d seruirse de hacerle merçed, de

\footnotetext{
${ }^{37}$ El Expediente Personal de Lázaro Díaz del Valle tiene cuatro documentos que se han numerado aquí de la "a" a la " $d$ ", respectivamente.

38 "Junta formada por altos dignatarios palatinos y presidida por el mayordomo mayor que resolvía los expedientes administrativos de la casa real y ejercía jurisdicción sobre las personas sujetas al fuero de ella" (D.R.A.E.L.).
} 
la pinsion o en otra $\operatorname{cosa}=$ Grefier $^{39}$ fran[cis]co de Venauides

Al margen: quedo con cuydado.

Señor

En Vn memorial remitido, al Marques de Santa Cruz refiere don lacaro del Valle y de la Puerta Mussico de la R[ea]l Capilla de V Mag[esta]d que â 16 anos $^{40}$ [sic, años] que sirue en ella con todo cuidado y asistencia y que, es sobrino y heredero de mas de 44 años de seruicios de xptoual [sic, Cristóbal] Gomez de la Puerta que murio siendo Vxier de saleta de la Reina n[uest]ra señora y de los de francisco Gomez de oliuera su tio que siruio a $\mathrm{V}$ Mag[esta]d mas de 56 años en plaças de cont[ador] de Resultas de Reçetor y pagador de los conssejos y en otras Por todo lo qual suplica, a V Mag[esta]d le haga merçed de la Racion que Vaco por muerte de d[ic]ho Cristoual Gomez. su tio (atento no auer dejado Viuda, ni hixos â quien se dar mas que al suplicante y de 200 ducados de pension eclesiastica $=$

Y auiendo se visto en el bureo parece que por todos estos seruicios merece ser premiado de V Mag[esta]d pero por q[ue] la despensa esta con muchas cargas podria V Mag[esta]d seruirse de hacerle merçed, de la pension que pide o en otra cosa al a que V Mag[esta]d fuere mas seruido. A 11 de março de $1638=$

39 "Oficio honorífico de la casa real, según la etiqueta de la de Borgoña, auxiliar y complementario del de contralor. En el bureo actuaba como secretario". (D.R.A.E.L.).

${ }^{40}$ Díaz del Valle, según este y el siguiente documento, debió llegar a la Corte hacia 1622 ó 1623, y entró en Palacio con 16 ó 17 años. En la Real Capilla entró diez años después de llegar a Madrid, en 1633, cuando contaba con 26 ó 27 años.
II. c) Bureo ${ }^{41}$ de la Reina n[uest]ra s[eñor]a A 8 de febrero de $1639=\mathrm{n}^{\mathrm{o}} 10$

Don lacaro del Valle y de la puerta pretende que $\mathrm{V}$ Mag[esta]d le haga $\mathrm{m}[\mathrm{e}] \mathrm{r}[\mathrm{ce}] \mathrm{d}$ en cosideracion de los seruicios que refiere de la Racion que Vaco por muerte de xptoual Gomez de la puerta su tio atento es su heredero y no dexo muger ni hijos que la pidan y el Bureo es de parecer que porque la despensa esta cargada podia V M[a]g[esta]d seruirse de encomendarle al consejo de camara Grefier fran[cis]co de Venauides

En el Bureo que se tubo a quatro deste se hico relacion de Vn memorial que don laçaro de Valle y de la Puerta Remitido por V M[a]g[esta]d al Marques de Santa cruz. en que Refiere que a 16 años que sirue a $\mathrm{V}$ Mag[esta]d en la plaça de musico de su Real Capilla con mucho cuidado y asistencia y que, es sobrino y eredero de mas de 44 años de seruicios de cristoual Gomez de la Puerta que murio el ano pasado de 638 siendo Vxier de saleta de la Reina n[uest]ra señora y de los de francisco Gomez de Ôliuera, su tio que siruio a V M[a]g[esta]d mas de 56 anos en las plaças de contador de Resultas Receptor y pagador de los consejos $\mathrm{y}$ en otras por todo lo qual suplica, a $\mathrm{V}$ $\mathrm{M}[\mathrm{a}] \mathrm{g}[\mathrm{esta}] \mathrm{d}$ le haga m[e]r[ce]d de la Racion que vaco por muerte del d[ic]ho critoual gomez de la Puerta su tio (atento no a dejado Viuda ni hijos a quien se dar mas que al suplicante) y de 200 ducados de Renta, al ano pagados por la cassa de Castilla o Vn decreto para que el consejo de Camara le consulte en Vna preuenda del Patronazgo R[ea]l

$\mathrm{y}$ auiendo visto el Bureo parece que por todos los seruicios y rraçones que Representa merece ser premiado de $\mathrm{V}$

\footnotetext{
${ }^{41}$ Este memorial se refiere a la documentación recogida en el Bureo anterior, de 11 de mazo de 1638 (doc. II.b).
} 
$\mathrm{M}[\mathrm{a}] \mathrm{g}[\mathrm{esta}] \mathrm{d}$ pero porque la despensa esta con muchas cargas y es fuerça buscar el aliuio della, antes que añadirle menos gastos podria $\mathrm{V} \mathrm{M}[\mathrm{a}] \mathrm{g}[\mathrm{esta}] \mathrm{d}$ seruirse de haçer la merced, del decreto que pide siruiendose V M[a]g[esta]d de, encomendarle por el, al consejo de camara para que tenga cuidado de su persona y le consulte, en alguna preuenda del Patronazgo Real conforme la calidad, y meritos de sus seruicios, o en otras cosas de su profess[i]on $\mathrm{V}$ $\mathrm{M}$ [a]g[esta]d mandara lo que fuere mas de su Real seruicio A 8 de febrero de 1639

Al margen: El Marq[ue]s de Santa cruz El Conde de la moncloua El Conde de figueroa

II. d) Bureo de sus alteças en Madrid a 25 de mayo de $1646 n^{\circ} 76^{42}$

Diçe la pretension que tiene Don laçaro balle de la puerta de la Real capilla de V Mag[esta]d, y por sus seruiçios y los de xptoual [sic, Cristóbal] de la puerta su tio Vxier de saleta que fue de la Reyna Nuestra Señora (que esta en el cielo) se le haga $\mathrm{m}[\mathrm{e}] \mathrm{r}[\mathrm{ce}] \mathrm{d}$ de una raçion ordinaria:

$\mathrm{Y}$ al bureo parece que por los seruicios que representa podria V. Mag[esta]d seruirse de hacerle $\mathrm{m}[\mathrm{e}] \mathrm{r}[\mathrm{ce}] \mathrm{d}$ de una pension eclesiastica de 150 ducados por su profesion hir [sic, ir] por la Yglesia: Grefier Manuel Munoz [sic, Muñoz] y Gamboa

\section{Señor}

En el bureo que se tubo en diez y ocho del corriente se uio un memorial de Don Lacaro balle de la puerta que sirue a $\mathrm{V}$ Mag[esta]d en su Real Capilla mas, a de beinte y tres años y Dice fue xptobal de la puerta su tio siruio de Vxier de saleta de la

\footnotetext{
${ }^{42}$ En este memorial se resuelven los memoriales anteriores, después de casi diez años, concediendo a Díaz del Valle una pensión eclesiástica de 150 ducados "por ser su profesion el hir [sic, ir] por la Yglesia".
}

Reyna n[uest]ra señora (que este en el cielo) mas de quarenta y quatro años en la thesoreria general y otros papeles y en la d[ic]ha Plaça de Vxier de saleta y fue siruiendo a la christianisima Reyna de francia ${ }^{43}$ de sumiller de la caua donde estubo beinte y dos messes hasta que por orden de V. Mag[esta]d, boluio a espana [sic, España] con los demas criados y se le hico $\mathrm{m}[\mathrm{e}] \mathrm{r}[\mathrm{ce}] \mathrm{d}$ de la d[ic]ha plaça de Vxier de saleta en la qual falleçio suplicando a $\mathrm{V}$ Mag[esta]d en su testamento que por sus seruicios hiciese V Mag[esta]d m[e]r[ce]d al d[ic]ho sobrino hijo de una hermana suya el qual suplica le haga m[e]r[ce]d de una Racion hordinaria para poderse sustentar y no hauer dexado otros herederos ni mujer a quien se le diese Raçion y hauer gastado el Patrimonio que heredo de sus padres en seruicio de V Mag[esta]d en su Real Capilla $=$ en que la Reciuira muy grande $=$

El bureo ${ }^{44}$ a reconocido los papeles que presenta Don Lacaro balle de la puerta y por ellos consta que xptobal [sic, Cristóbal] de la puerta su tio fue receuido en diez $\mathrm{y}$ siete de otubre de mil y seiscientos y quince por sumiller de la caua de la Christianisima Reyna de francia hasta que boluio con orden de V Mag[esta]d y se le hiço $\mathrm{m}[\mathrm{e}] \mathrm{r}[\mathrm{ce}] \mathrm{d}$ de la plaça de Vxier de saleta de sus alteças en siete de Jullio de mill y seiscientos y diez y siete donde siruio con aprobacion de sus superiores hauiendosele encargado fuera de lo que le tocaua por su oficio otras cosas de que dio siempre muy buena quenta y todo lo hiço con mucho lucimiento de su persona hasta que murio tambien consta hauerle dexado por herede-

\footnotetext{
${ }^{43}$ Se refiere el documento, por su fecha, a la Reina de Francia, Ana de Austria, y no a la infanta María Teresa, como apuntaba López Castrillón en su artículo tan citado.

${ }^{44}$ En las líneas que siguen se especifican los datos del servicio de Cristóbal Gómez de la Puerta, tío de Díaz del Valle, en palacio, primero como sumiller de la cava y después como ujier de saleta.
} 
ro de sus seruiçios y asi pareçe podria seruirse $\mathrm{V}$ Mag[esta]d de hacerle $\mathrm{m}[\mathrm{e}] \mathrm{r}[\mathrm{ce}] \mathrm{d}$ de una pension eclesiastica de ciento y cinquenta ducados por ser su profesior el hir por la Yglesia en todo mandara $\mathrm{V}$ Mag[esta]d lo que mas conbenga de su Real seruiçio en madrid A 25 de Mayo de $1646=$

Al margen: Marques de Santa Cruz Conde de figuero Conde de Mora Baylio de Lora Marques de Monrroy

III) AGP, Expedientes Personales, $\mathrm{C}^{\mathrm{a}}$ 633/19: Expediente Personal de Agustín Martínez.

Lazaro del Valle cantorçico fue Reciuido por cantor en 25 de Diziembre de 633 como p[arec]e quel $\mathrm{d}$ [ic]ho libro [se refiere al Libro de Asientos del grefier Carlos Sigoney].

Al margen: En prim[er]o de hen[er]o de 641 se le hizo m[e]r[ce]d de Vna plaza ordinaria por aumento.

IV) AHPM, Prot. 9469, Esno. Juan de Siles Calahorra, fols. $145 \mathrm{r}-148 \mathrm{v}$ : testamento de Lázaro Díaz del Valle y de la Puerta, 26 de febrero de 1669 .

En el Nombre de Dios amen $=$ SEPan quantos esta Carta de testam[en]to y Vltima Voluntad Vieren como Yo Don Lazaro Diaz del Valle y de la Puerta Criado de su Mag[esta]d en su R[ea]l Capilla y Coronista General destos Reynos hijo legitimo de los s[eño]res Bar[tolo]me del Valle El Viejo y D[oñ]a Maria de la Puerta su mug[e]r mis Padres ya difuntos Vecinos que fueron de la Ciu[da]d de Leon e yo resid[en]te en esta Corte y Villa de Madrid estando enfermo en la cama de la enferm[eda]d corporal que Dios n[uest]ro s[eñ]or a sido seruido darme por sano de mi Juicio y entendim[ien]to natural $[\ldots]=$ Otorgo que hago y ordeno $\mathrm{mi}$ testam[en]to y Vltima Voluntad en la forma y manera siguiente -

\section{$[\ldots]$}

Quan[do] Dios n[uest]ro s[eño]r fuere seruido de llebarme de la press[en]te Vida mando que mi Cuerpo sea conpuesto [sic, compuesto] y amortaxado con el hauito de mi Padre s[a]n fran[cis] $\mathrm{co}^{45}$ y que se depossite en el Combento R[ea]l de los Angeles desta Villa de Madrid. Y despues se lleue en secreto a la Ciu[da]d de Leon y se ponga en la Iglesia del Combento R[ea]l de Monjas que llaman de Caruajal orden de San Benito de la d[ic]ha ciu[da]d en la forma que adelante se dira -

La forma de mi Entierro y disposs[ici]on de El la dexo a la de mis testamentarios para que se haga y disponga como mejor les parezca -

Digansse Dos mill seteçientas y quinze misas de Alma = las Dos mill de ellas por la quinientas por las de mis Padres y Abuelos Ciento por la de Doña melchora del Valle mi hermana ya difunta $=$ otras ciento por las animas de Purgatorio y por algun cargo le tubiere $=\mathrm{Y}$ las quince missas restantes por mi intencion -

A las Mandas pias forzossas acostumbradas mando Seis Reales para todas con que las excluyo y aparto del derecho de mis Vienes -

Yten es mi Voluntad de fundar como press[en]te fundo Vna Memoria de Vna Missa rezada cada dia que se a de decir perpetuam[en]te a las Doze dadas en el d[ic]ho Combento R[ea]l de Religiosas de San Benito que llaman de Caruajal de la

\footnotetext{
${ }^{45}$ Lázaro Díaz del Valle fue especialmente devoto de San Francisco. Lo apuntado en el testamento, las memorias de misas que dejó por cláusula en aquél y los documentos conservados en el convento de Santa María de Carbajal de León, en que se le llama "licenciado" (doc. XI), afianzan la posibilidad de que nuestro personaje pudiera tomar órdenes religiosas, aunque no se conserve documentación específica al respecto.

Hasta donde hemos podido revisar la documentación, se puede afirmar que todas las disposiciones testamentarias de Díaz del Valle se cumplieron.
} 
d[ic]ha Ciu[da]d de Leon por mi Alma y por las de mis Padres y Abuelos y por las de purgatorio para cuyo efecto se daran de mi hacienda a el d[ic]ho R[ea]l Combento Dos mill ducados de Vellon por Vna Vez obligandose a el Cumplim[ien]to de la $\mathrm{d}[\mathrm{ic}]$ ha memoria de hacer decir en el la d[ic]ha Missa rezada cada dia a las Doze dadas -

Asimismo es mi Volunt[a]d que quando se traslade mi cuerpo a la d[ich]a Ciu[da]d de Leon se ponga en la Yglessia de d[ic]ho Combento de Monjas de San Benito de Caruajal en parte decente conforme a mi Calidad con vn epitaphio de Alauastro que sea de fixar en la pared con letras negras que diga assi -

Aquí Yaze Don Lazaro Diaz del Valle y de la Puerta natural desta Ciu[da]d de Leon y criado del Rey n[uest]ro s[eño]r Phelipe quarto en su R[ea]l Capilla y su Coronista general en estos Reynos de España el qual por grande deuocion que tuuo a n[uest]ro Padre San Benito y a este Santo Combento se mando trasladar a el desde el R[ea]l de los Angeles de Madrid donde fue depositado en tantos de tal mes y tal año y aquí fue trasladado en tanto de tal mes y tal año dexo Vna Memoria de Vna Missa perpetua cada dia que se a de decir en este santo Combento a las Doze dadas rueguen a Dios por el y En Cima del d[ic]ho epitaphio se pondran Dos Pinturas que tendo y mando para este efecto que la Vna esta en mi Cassa y es del descendimiento de la Cruz $=\mathrm{Y}$ la otra es de la Resurreccion de Lazaro de Mano de Don Juan Antonio escalante en cuyo poder esta por no tenerla acauada y se la tengo pagada y asi encargo a el susso d[ic]ho la acabe con la perfeccion que me tiene ofrecida: $y$ a mis testamentario que le den en estando acauada cinq[uen]ta Reales de Vellon por Vna uez p[ar]a Vn regalo -
Yten Mando a el d[ic]ho Combento R[ea]l de Monjas de San Benito de Caruajal Vna Ymagen que tengo de bulto de n[uest]ra s[eño]ra de la Concep[ci]on ${ }^{46}$ con su peana dorada y Angeles que a muchos dias que la tengo ofrecida a el d[ic]ho combento y encargo a las Religiosas del me encomienden a Dios -

Declaro que en el Combento de S[a]n fran[cis]co de la d[ic]ha Ciu[da]d de Leon ay Vna Memoria que fundaron mis passados con Doze Ducados de renta a el año es mi Volunt[a]d que de mi hacienda se de a el d[ic]ho Combento el Prin[cipa]l de otros Doze Ducados de renta para que no Vaya a menos la d[ic]ha Memoria y la Cumpla puntualm[en]te haciendo p[ar]a ello revalidacion y nueua obligacion -

A Doña Jacinta de Valle y de la Puerta mi herm[an]a Religiossa professa en el d[ic]ho combento de San Benito de Caruajal de la d[ic]ha ciu[da]d de Leon la mando trecientos Ducados de Vellon por Vna Vez ${ }^{47}$

A D[oñ]a Paula Diaz del Valle asimismo mi herm[an]a Viuda uecina de la d[ic]ha Ciu[da]d de Leon la mando quinientos Ducados de Vellos por Vna Vez -

A D[oñ]a Paula fernandez del Valle mi sobrina hija de la d[ic]ha D[oñ]a Paula mi herm[an]a y mug[e]r de Don fernando de Oliuera señor del Mayorazgo de quintana de Raneros la mando quinientos Ducados de V[ello]n por Vna Vez -

Yten Es mi Voluntad que de toda la hacienda que tengo y me pertenece en la d[ic]ha Ciu[da]d de Leon sea Vsufructuaria por los dias de su vida la d[ic]ha D[oñ]a

\footnotetext{
${ }^{46}$ El convento la vendió después por 500 reales para afrontar algunas deudas y por haber en el cenobio otra del mismo asunto (doc. XI).

${ }^{47}$ Jacinta del Valle cobró su herencia el 22 de mayo de 1669 (doc. VII).
} 
Paula Diaz del Valle mi herm[an]a y despues de hauer fallecido la susso d[ich]a se agregue a el d[ic]ho Mayorazgo de quintana de Raneros que possee el d[ic]ho Don fernando de oliuera $=\mathrm{Y}$ asimismo es $\mathrm{mi}$ Volunt[a]d que todo lo que su Mag[esta]d me quedare debiendo de mis gaxes y distribuciones que sera asta trece o catorce mill Reales se cobre y se emplee de renta de la qual a de gozar por su Vida la d[ic]ha D[oñ]a Paula Diaz del Valle mi herm[an]a y despues de sus dias a de quedar tan bien agregada a el d[ic]ho Mayorazgo de quintana de Raneros -

A la d[ic]ha Ciudad de Leon por el mucho amor y Volunt[a]d que la tengo y ser hijo della la mando Dos libros que tengo escritos en pergamino y otro que es tercera parte que esta empezado de la historia de la nobleza del Reyno de Leon y Principado de Asturias $^{48}$ -

Declaro que tengo Otro libro escrito de mi mano con iluminaciones que se intitula nobleza en sangre y heroicas Virtudes del Rey n[uest]ro s[eño]r Phelipe quarto que esta en poder del s[eño]r Don Pedro fernandez del campo secretario de estado de su Mag[esta]d encargo a Juan Diaz Rodero mi Amigo mercader de sedas de su Mag[esta]d le cobre y que lo que se beneficiara del lo distribuya en obras pias a su disposs[ici]on conforme lo que le tengo comunicado -

Al d[ich]o Juan Diaz Rodero mi Amigo le mando vn Arcabuz que tengo que es de Gaspar y Simon y vn espadin de dos que tengo el que eligiere -

A fran[cis]co Louera mi Amigo m[aest]ro de torcer sedas le mando Vn estoque de estima que tengo y a Doña fran[cis]ca Canta loba su mug[e]r que me a asistido en mi enferm[eda]d la mado [ta-

\footnotetext{
${ }^{48}$ Vid. nota 33
}

chado, Dos Piezas de Cambray que tengo: y otras] Dos piezecillas de olanda de a ocho o nueue Varas: y Vn Escritorillo de Cañamazo -

A Joseph Hidalgo mi amigo le mando Vna espada que tengo acanalida [sic, acanalada] asta la punta -

A Maria fernandez mi Criada la mando Cien Reales de V[ello]n por Vna Vez: Vna frazada y Dos Colchones con lana Vno de terliz y otro blanco draydo y se la pagara lo que le debiere de los tres Reales que le doy cada dia -

Y Para cumplir y Executar este mi testam[en]to mandas y legados dexo y nombro mis Albaceas y testamentarios a los d[ic]hos Juan Diaz Rodero francisco Lobera y Joseph Hidalgo mis Amigos a los quales y a cada Vno in solidum doy poder como de der[ech]o se reg[ul]e p[ar]a que se entren en mis Vienes y los Vendan y rematen en pu[bli]ca almoneda o fuera de ella como les pareciere y reciban y cobren todo quanto se me deue y debiere lo qual puedan hacer aunque sea pass[a]do el año del Albaceazgo porque yo les prorrogo el $\mathrm{d}[\mathrm{ic}]$ ho cargo por todo el $\mathrm{t}[\mathrm{iem}]$ po que quisieren vsar del $=\mathrm{Y}$ es mi Voluntad que lo que yo tubiere en din[er]o plata y oro y lo demas que procediere de mis Vienes entre en poder del d[ic]ho Juan Diaz Rodero para que se cumpla lo contenido en este mi testam[en]to -

Y Cumplido y pagado en el Remanente que quedare de todos mis Vienes dexo nombro e instituyo por mi Heredera a mi Alma por la qual se ha ran decir las missas y sufraxios a que alcazare el d[ic]ho Remanente a eleccion de mis testam[enta]rios -

Y Reuoco y anullo y doy por ningunos otros qualesquier testamentos codicillos Poderes p[ar]a testar Mandas y legados que antes deste aya hecho y otorgado por escrito o de palabra que quiero que no Valgan 
no hagan fee en Juicio ni fuera del saluo este que al presente otorgo que quiero que Valga por mi testam[en]to y Vltima Volunt[a]d o en la Via $y$ forma que en der[ech]o mejor lugar aya $\mathrm{Y}$ asi lo otorgo ante el press[en]te escriu[an]o y testigos en la Villa de Madrid vey[n]te y seis dias del mes de Febrero de mil y seis[cient]os y sessenta y nueue años siendo testigos llamados y rogados Jaçinto Ruiz Brauo Bernaue de monforte Gabriel Perez Pedro de Sant[iago] y fran[cis]co Martinez res[iden]tes en esta corte e yo el [e]s[criba]no que doy fee conozco a el otorg[an]te dixo no poder firmar por la grauedad de su enferm[eda]d a su ruego lo firmo vn testigo $=\mathrm{Ba}[. .$.$] testado =$ Dos piezas de Cambray que tengo y otras $=$ no vale $=$

Por testigo Jaçinto Ruiz brauo

Ante mi

Juan de Siles [rubricado]

V) AHDM, Sección Parroquias, Madrid, San Martín, Libro de difuntos 8, fol. 25v: partida de defunción de Lázaro Díaz del Valle en San Martín de Madrid, 27 de febrero de 1669.

En 27 de febrero de 1669 murio D. lazaro Diaz del Valle y de la Puerta Choronista de su Mag[esta]d Calle de Silua Cassa de $\mathrm{D}$ [oñ]a Catalina de Vlloa R[ecibi]o los santos sacramentos testo en 26 deste ante Joan de Siles Calahorra Escriu[an]o R[ea]l testamentario Joan Diaz Rodero a la puerta de Guadalajara Cassa de los Quiresses, fran[cis]co Lobera Calle de Silua Cassa de Villandrando y Joseph Ydalgo dicha Calle Cassa propia, testo de dos mil setecientas y quince Missas depositose en los Angeles, Alma heredera -

Al margen: Angeles.

Al margen derecho: 66.
VI) AHPM, Prot. 9469, Esno. Juan de Siles Calahorra, fols. 154r-154v: depósito del cadáver de Lázaro Díaz del Valle en el Convento Real de Santa María de los Ángeles de Madrid, 28 de febrero de $1669^{49}$.

En la Villa de Madrid a Vey[n]te y ocho dias del mes de febr[er]o de mil y seis[cient]os y sessenta y nueue años estando en el Combento R[ea]l de los Angeles que es de Religiossas del orden de San fran[cis]co ante mi el s[criba]no pu[blic]o y testigos parecio la s[eñor]a D[oñ]a Anto[ni]a de Velasco Abadessa del $=\mathrm{Y}$ dixo que Don Lazaro Diaz del Valle y de la Puerta Criado de su Mag[esta]d en su R[ea]l Capilla y Coronista destos Rey[n]os por su testam[en]to que otorgo ante mi el pres[en]te año en vey[n]te y seis deste pres[en]te mes y año Mando que su Cuerpo fuesse depositado en la Iglessia del d[ic]ho $\mathrm{R}$ [ea]l Combento p[ar]a que de alli se trasladasse y llebasse a la ciu[da]d de Leon en la forma que se contiene en el d[ic]ho testam[en]to deuajo de cuya disposs[ici]on murio y su Cuerpo se deposito ayer Veinte y siete deste mes en la Vobeda del d[ic]ho comb[en]to Cuyo Depossito [entre líneas, y otros gastos] se concerto en Mill Reales de Vellon los quales la d[ic]ha s[eñor]a Abadessa confiessa hauer reciuido de Juan Diaz Rodero Mercader de sedas de su Mag[esta]d como testamentario del d[ic]ho Don Lazaro Diaz del Valle de que se dio por contenta y entregada a toda su volunt[a]d con renunciacion de las leyes de la entrega prueba della y demas del casso y dellos dio y otorgo carta de pago en fauor

\footnotetext{
${ }^{49}$ El convento de Santa María de los Ángeles de Madrid, de religiosas franciscanas, fue fundado en 1564. No se conserva hoy día, pues fue demolido hacia 1838, como cuenta Mesonero Romanos en “EL / ANTIGUO MADRID, / PASEOS HISTÓRICOANECDÓTICOS / POR LAS CALLES Y CASAS DE ESTA VILLA, / POR / D. RAMON DE MESONERO ROMANOS. / MADRID: / ESTABLECIMIENTO TIPOGRAFICO DE DON F. DE P. MELLADO, / calle de santa Teresa número 8. / 1861", p. 96.
} 
del d[ic]ho Ju[an] Diaz Rodero tan bastante $\mathrm{y}$ firme como a su der[ech]o combenga $=\mathrm{Y}$ obliga a el $\mathrm{d}[\mathrm{ic}]$ ho combento a que por razon del d[ic]ho Don Lazaro Diaz del Valle si quisiere sacar el cadauer del susso d[ic]ho o sus huessos se dejara sacar librem[en]te sin impedim[en]to alg[un]o p[ar]a lo qual obligo en for[m]a a el d[ic]ho combento y dio poder a las Inst[anci]as competentes p[ar]a la exe[cuci]on de lo referido $\mathrm{p}$ [ar]a que lo hagan cumplir [...] Y asi lo otorgo siendo testigos Don Martin de Zoldi Ant[oni]o Diaz y Man[ue]l Martinez re[siden]tes en esta Corte y la d[ic]ha s[eño]ra Abbadessa otorg[an]te a q[uie]n yo el s[criba]no doy fe conozco lo firmo = entre $\mathrm{r}$ [englone $] \mathrm{s}=\mathrm{y}$ otros gastos

doña antonia de belasco abb[ades]a

Ante mi

Juan de Siles [rubricado]

VII) AHPM, Prot. 9469, Esno. Juan de Siles Calahorra, fols. 495r-495v: Fernando de Torres cobra, en nombre de Jacinta Díaz del Valle, hermana de Lázaro Díaz del Valle, 3300 reales por cláusula testamentaria, 22 de mayo de 1669.

En la Villa de Madrid a Veinte y dos dias del mes de Mayo de mil y seis[cient]os y sessenta y nueue años ante mi el escriu[an]o y testigos parecio Don fernando de torres v[e]z[in]o desta Villa en nom[br]e de Doña Jacinta Diaz del Valle y de la Puerta Religiosa professa en el Combento de Santa Maria del Carbajal de la orden de San Benito de la ciu[da]d de leon y en virtud del poder que suyo tiene especial para cobrar la cant[ida]d que adelante se dira otorgado ante Bar[tolo]me Lopez nauia s[criba]no del num[er]o de la d[ic]ha Ciudad a Diez y seis deste pres[en]te mes y año como por el parece que orig[ina]l con el tras[la]do desta carta de pago entrega y declara que es cierto y verdadero y que no le esta reuocado del qual vssando $=$ confesso hauer reciuido de Juan Diaz Rodero mercader de sedas de su Mag[esta]d como testamentario que es de Don Lazaro Diaz del Valle y de la Puerta ya difunto criado que fue de su Mag[esta]d y su Coronista g[enera]l destos Rey[n]os tres mil y trecientos Reales de v[ell]on que le a pagado por tantos que el d[ic]ho Don Lazaro Diez del Valle por vna clausula de su testam[en]to con que murio que otorgo ante mi el pres[en]te escriu[an]o a veinte y seis de febrero deste pres[en]te año de xo [sic, Cristo] y mando a la d[ic]ha $\mathrm{D}$ [oñ]a Jacinta Diaz del Valle su hermana como parece por el d[ic]ho testam[en]to a que se remite $=$ De los quales $\mathrm{d}[\mathrm{ic}]$ hos tres mil $\mathrm{y}$ trecientos Reales de v[ell]on se dio por contento y entregado a toda su voluntad [...] y dellos dio y otorgo carta de pago en fauor del d[ic]ho Ju[an] Diaz rodero tan bastante y firme como a su derecho combenga siendo testigos Andres Merino Joseph Vidarte y Luis Zorrilla res[iden]tes en esta corte e yo el esciu[an]o [sic] que doy fee conozco a el otorg[an]te que lo firmo $=$

\section{Al margen: 3.300 R[eale]s}

f[ernan]do de torres

Ante mi

Juan de Siles [rubricado]

VIII) AHPM, Prot. 9469, Esno. Juan de Siles Calahorra, fols. 609r-609v: Juan Díaz Rodero cobra 29520 mrs. de gajes de Lázaro Díaz del Valle, por disposición testamentaria, 12 de junio de 1669.

En la Villa de Madrid a doze dias del mes de Junio de mil y seis[cient]os y sesenta y nuebe años ante mi el escriuano publico y testigos pareçio Juan Díaz Rodero Mercader de Sedas de su Mag[esta]d como testamentario ynsolidum que es de Don Lazaro Diaz del Valle ya difunto nombrado por tal en su testamento y vltima Voluntad debajo de Cuya disposicion fallecio que otorgo ante mi el presente escriuano en beynte y seis de febrero deste presente año 
de que doy fe y como tal testamentario $=$ Confeso haber reçibido de Juan Perez de zumelzu thesorero de la Capilla real de su Mag[esta]d Veynte y nuebe mil quinientos y Veynte marabedis de Vellon que le a pagado por tantos que en el Rol de Gajes de la d[ic]ha real Capilla del terçio Segundo del año pasado de mil y seisçientos y sesenta y ocho su f[ec]ha a Veynte y siete de Abril deste presente año se libraron en el $\mathrm{d}[\mathrm{ic}] \mathrm{ho}$ Juan Perez de zumelzu a la parte del d[ic]ho Don Lazaro Diaz del Valle como parece por $\mathrm{d}[\mathrm{ic}]$ ho Rol a que se remite $=\mathrm{De}$ los quales d[ic]hos Veynte y nuebe mil quinientos y Veynte marabedis de Vellon se dio por contento y entregado a toda su Voluntad [...] y dellos dio y otorgo Carta de pago en fabor del d[ic]ho Juan Perez de zumelzu tan bastante y firme como a su $\mathrm{d}[\mathrm{e}] \mathrm{r}[\mathrm{ech}] \mathrm{o}$. Combenga siendo testigos Joseph Mateo Pedro Perez y Luis zorrilla resientes en esta Corte e yo el escribano que doy fe conozco a el otorgante que lo firmo=

Ju[an] Diaz Rodero

Ante mi

Juan de Siles [rubricado]

IX) AHPM, Prot. 9469, Esno. Juan de Siles Calahorra, fols. 741r-742r: reparto del dinero sacado de la venta de bienes de Lázaro Díaz del Valle entre los testamentarios, 19 de julio de 1669.

En la Villa de Madrid a Diez y nuebe dias del mes de Jullio de mil y seiscientos y sessenta y nueue años ante mi el escriuano pu[bli]co y testigos parecieron Joseph Hidalgo y fran[cis]co Lobera vecinos desta Villa $=\mathrm{Y}$ dixeron que Juan Díaz Rodero Mercader de sedas de su Mag[esta]d y los d[ic]hos Otorgantes y cada vno insolidum quedaron por testamentarios de Don Lazaro Diez del Valle y de la Puerta ya difunto Criado que fue de su Mag[esta]d y su Coronista general destos Reynos: $\mathrm{Y}$ el d[ic]ho Juan Diaz Rodero se encargo de hacer im- bentario del din[er]o y Plata labrada que quedo por muerte del d[ic]ho Don Lazaro el qual d[ic]ho din[er]o y plata labrada entro en poder del d[ic]ho Juan Diaz que de ello se hizo cargo en el d[ic]ho Imbentario = Y los d[ic]hos Joseph Hidalgo y fran[cis]co Lobera se encargaron de hacer Imbentario tassacion y Almoneda de los demas Vienes muebles que quedaron del d[ic]ho Don Lazaro de que tambien se hicieron Cargo en el d[ic]ho Imbantario: $\mathrm{Y}$ habiendo hecho Venta y Almoneda de ellos importo su procedido Veinte y vn mill ocho çientos y ochenta y quatro Reales de v[ell]on de que los d[ic]hos Otorgantes se hicieron Cargo como consta de las partidas contenidas en la Almoneda y Venta de los d[ic]hos Vienes a que se remiten $=\mathrm{Y}$ para que Conste que Cant[ida]d para y esta en poder de cada vno de los d[ic]hos Otorgantes: Dixeron y declararon que de los d[ic]hos Veinte y vn mill ochoçientos y ochenta y quatro Reales que como esta d[ic]ho importo la Venta de los d[ic]hos Vienes paran y estan en poder del d[ic]ho Joseph Hidalgo los siete mill Reales de Vellon de ellos $=\mathrm{Y}$ los Catorce ochocientos y ochenta y quatro R[eale]s restantes paran y estan en poder del d[ic]ho francisco Louera de las quales d[ic]has cantidades cada vno de los d[ic]hos otorg[an]tes por lo que le toca se dieron por contentos y entregados a toda su volun[ta]d [...]: Y se constituyen por Depositarlos y a ley de Deposito y so la pena del de los $\mathrm{d}[\mathrm{ic}]$ hos Veinte y vn mill ochocientos y ochenta y quatro Reales de v[ell]on en esta man[er]a de los Siete mill Reales de ellos; el d[ic]ho Joseph Hidalgo y de los catorce mil ochocientos y ochenta y q[ua]tro R[eale]s restantes el d[ic]ho fran[cis]co Louera: y se obligan a que los tendran de manifiesto $\mathrm{p}$ [ar]a entregarlos a el d[ic]ho Juan Diaz Rodero como Perss[on]a en cuyo poder deue entrar (conforme a la disposs[ici]on del d[ic]ho Don Lazaro Diaz del Valle) lo que procediere de la $\mathrm{d}[\mathrm{ic}] \mathrm{ha}$ testamentaría. y cada vno de los d[ic]hos Otorg[an]tes 
pagara la Cant[ida]d que le toca en moneda Vsual y corriente a el t[iem]po del entrego sin Vaja ni desquento alg[un]o a lo qual se les a de poder apremiar por todo rigor de derecho $=$ Y Para que lo cumpliran obligaron sus Perssonas y Vienes hauidos y por hauer $=\mathrm{Y}$ dieron poder a las Just[ici]as de su Mag[esta]d de qual q[uie]r Juris[dicci]on que sean y especial [...] y otorgaron Deposito $\mathrm{y}$ oblig[aci]on en forma ante $\mathrm{mi}$ el ss[criba]no siendo testigos fran[cis]co Hernandez Martin Garcia y Pedro Sierra ress[iden]tes en esta corte e yo el ss[criba]no que doy fe e conozco a los Otorg[an]tes que lo firmaron $=$

$$
\begin{aligned}
& \text { Joseph Hidalgo } \\
& \text { francisco lobera }
\end{aligned}
$$

Ante mi

Juan de Siles [rubricado]

X) AHPM, Prot. 9469, Esno. Juan de Siles Calahorra, fol. 745: Juan Díaz Rodero cobra 29280 mrs. de gajes de Lázaro Díaz del Valle, por disposición testamentaria, 20 de julio de 1669.

En la Villa de Madrid a Veynte dias del mes de Julio de mil y seis[cient]os y sesenta y nuebe años ante mi el escriuano publico y testigos parecio Juan Diaz Rodero Mercader de sedas de su Mag[esta]d como testamentario ynsolidum que es de Don Lazaro Diaz del Valle ya difunto nombrado portal en su testamento con que murio que otorgo ante mi el presente escriuano en Veynte y seis de febrero deste presente año de que doy fe $=Y$ Confeso haber reçibido de Juan Perez de Zumelzu thesorero de la Capilla real de su Mag[esta]d Veynte y nuebe mil Duçientos y ochenta $\mathrm{m}[\mathrm{a}] \mathrm{r}[$ avedí]s de Vellon que le a pagado por tantos que en el Rol de Gajes de la $\mathrm{d}[\mathrm{ic}]$ ha real Capilla del tercio vltimo del año pasado de mil y seis[cient]os y sesenta $\mathrm{y}$ ocho su f[ec]ha a Diez y ocho de Junio deste presente año se libraron en el d[ic]ho Juan
Perez de Zumelzu a la parte del d[ic]ho Don Lazaro del Valle como pareze por $\mathrm{d}[\mathrm{ic}]$ ho $\mathrm{Rol}$ a que se remite $=$ De los quales d[ic]hos Veynte y nuebe mil Duçientos y ochenta $\mathrm{m}$ [a]r[avedí]s de Vellon se dio por contento entregado a toda su Voluntad con renunçiaçion de las leyes de la entrega prueba della y demas del Caso y dellos dio y otorgo carta de pago en fabor del d[ic]ho Ju[an] Perez de Zumelzu tan bastante y firme como a su d[e]r[ech]o combenga siendo testigos Andres Merino Joseph Vidarte y Anbro[si]o fernandez residentes en esta Corte e yo el escriuano que doy fe conozco a el otorgante que lo firmo =

$$
\text { Ju[an] Diaz Rodero }
$$

$\mathrm{A}[\mathrm{n}]$ te $\mathrm{mi}$

Juan de Siles [rubricado]

Al margen: $29.280 \mathrm{~m}[\mathrm{a}] \mathrm{r}[$ avedí]s

XI) ASMC, Libro de Acuerdos 1, fols. 18-19: disposiciones del Convento de Santa María de Carbajal de León referentes al testamento de Lázaro Díaz del Valle, s. d.

En el año de 1669 Por muerte de el Liz[encia]d $\mathrm{d}^{50} \mathrm{D}$ Lacaro de el balle Coronista que fue de su Mag[esta]d Y M[aestr]o desu R[ea]l capilla $\mathrm{Y}$ por el testam[en]to debaxo decuia disposic[i]on murio mando $\mathrm{q}[\mathrm{ue}]$ de sus bienes se diessen a D[oñ]a Jacinta de el balle Religiosa professa en este Conuento Y Herm[an]a de el suso dicho, trecientos ducados de Vellon $\mathrm{Y}$ con efecto se le entregaron alasuso d[ic]ha Laqual Habiendo reconocido La necesidad con que se allaba $\mathrm{d}[\mathrm{ic}] \mathrm{ho}$ conu[ent]o Lessocorrio con los tres mill $\mathrm{Y}$ zien R[eale]s $\mathrm{Y}$ dicha ss[eñor]a Abbadessa tomo por su q[uen]ta socorrer a D[ic]ha ss[eñor]a doña Jacinta

\footnotetext{
${ }^{50}$ Se han hecho ya algunas reflexiones sobre este documento en líneas anteriores, pues es en el único en que se llama a Díaz del Valle "licenciado" y, además, Maestro de la Real Capilla (vid. doc. IV).
} 
caday quando quetubiesse necessidad $\mathrm{Y}$ de enterrarla como con efecto lo hiço Hasta el dia 20 de diz[iembr]e de el año passado de 1669 que fue Dios Seruido dellebarsse para si a d[ic]ha doña Luissa del balle Como consta de las dos planas antezedentes

En el dicho año de 1669 dicha s[eño]ra D[oñ]a Ysidora florez Abb[ades]a Habiendo tenido noticia que el d[ic]ho D. Lacaro del balle estaua muy rico y quese exercitaua en obras de mucha piedad socorriendo alos pobres $\mathrm{Y}$ menesterosos Le comunico por carttas Ynsinuandole en ellas Lo graue deeste conu[en]to $\mathrm{Y}$ los apriettos en quese allaba, deque rresultor que habiendo Le dado Dios la enfermedad de que murio mouido de auxilio suios $\mathrm{Y}$ de los grandes encarecim[ien]tos conq[ue] D[ic]ha ss[eñor]a Le habia escrito en orden a d[ic]ho socorro por su testam[en]to debajo de cuia disposiçion mando sefundasse en este conu[en]to vna missa reçada cada dia $Y$ por ella mando se diessen dos mil ducados debellon por la primera Vez Y Con afecto Hauiendo precedido La lizenzia de su ss[eñorí]a Yll[ustrísim]a $Y$ demas requisitos necess[ari]os se efectuo La d[ic]ha fundacion $\mathrm{Y}$ donazion demissa $\mathrm{Y}$ su Yll[ustrísi]ma El d[ic]ho s[eñ]or Don fr. $\mathrm{Ju}[\mathrm{an}]$ de toledo Reconoçiendo Los empeños conquese allaba el conu[en]to dio Licenzia para q[ue] delos d[ic]hos dos mil ducados segastassen la mittad empagar deudas $Y$ los otros mil se pusiessen açensso Como todo ello mas Largam[en]te consta dela d[ic]ha dotacion testam[en]to Lizenzias $Y$ demas papeles que pasaron Por el testim[oni]o de Bar[tolo]me Lopez Nauia ss[criba]no de el num[er]o Y Haudienzia $\mathrm{R}$ [ea]l desta ciu[da]d Y en ella a fines de Junio de El año de 1670

Por el testam[en]to debaxo de cuia disposicion murio el $\mathrm{d}[\mathrm{ic}]$ ho Liz[encia]do Don Laçaro del Valle bien echor de este conu[en]to mando colocar sus Huessos aesta santa cassa $Y$ que se le senalasse pues- to dezente adonde sepusiesen con vna piedra y epitafio, mando se diesse La cantidad quesustestamentarios $\mathrm{Y}$ Albazeas ajustassen con d[ic]ho Conu[en]to yabiendo Venido aesta ciudad sushuessoss d[ic]ha ss[eño]ra Abb[ades]a y demas Capitulares de el se combinieron en darle Lugar dezente a donde nichearon $Y$ se pusso la d[ic]ha piedra $\mathrm{Y}$ aunquepor ello se debia gran summa de $\mathrm{m}$ [a]r[avedí]s attendiendo asubuenzelo ya hauersido el suso d[ic]ho hombre degrandes prendas se modero en seisceintos duc[ad]os quesepagaron de contado y se consumieron en el desempeño de esta cassa El qual en execucion de su buenzelo mando para el adorno deesta Ygl[esi]a dos pinturas las desu maior estimaz[ion] que la Vna es del milagro grande que christo nuestro redentor Hiço Con [tachado] Laçaro a instanzia de sus hermanas. $\mathrm{Y}$ otro desu preciossissima descenssion dela cruz que son de muy subido precio $Y$ estimaz[i]on de esta cassa assi por sus grandes realzes, como por benir de mano de vn tambuen echor $=\mathrm{Y}$ assi mismo nos dio otra echura de n[uest]ra ss[eñor]a de la concepz[i]on La qual por allarsse al press[en]te otra del mismo genero en este conu[en] to $Y$ por combenir al desempeño deel Yser Laque en el ay de mucha debozion sedio emprecio de quinientos R[eale]s que se gastaron empagar algunas deudas muy precissas. Y para que en todo tiempo Conste del buenzelo de este bien echor $\mathrm{Y}$ que por las ss[eñor]as Abb[ades]as y demas capitulares de este ConV[en]to encomienden aDios n[uest]ro señor ald[ic]ho D. Laçaro de El balle $\mathrm{d}$ [ic]ha ss[eñor]a Abb[ades]a mando poner en este su libro de autoss capitulares esta aduertenzia y de la pintura del dezendim[ien]to Hazer vn altar Junto a la rreja de el coro $\mathrm{Y}$ inmediato al sitio $\mathrm{Y}$ lug[a]r donde esta Los huessos del suso d[ic]ho que santa gloria aya.$=$

Y lo firmo la secretaria De Deposito en Dicho año 
$\mathrm{D}[\mathrm{oñ}] \mathrm{a}$ anna De belasco y quiñones

Al margen: Aniu[ersari]o del liz[encia]do D. Lazaro del Valle (fol. 18v).

XII) ASMC, Libro de Cuentas 3, fol. 167v: gastos del nicho de Lázaro Díaz del Valle en la iglesia del Convento de Santa María de Carbajal de León, s. d.

mas se le cargan seiscienttos ducados. que su m[erce]d Cobro de los testamentarios de D. Lazaro de el valle en que se convino el convento. Por el nicho que se avrio en la yGlesia Para poner Los guessos de el d[ic]ho D. Lazaro de el valle que este en el cielo

$\mathrm{Y}$ ansimes mo se le cargan Dos mil ducados quel d[ic]ho D. Lazaro Dejo mandados Por su testamentto Para la fundacion de Vna [tachado, memoria Y] capellania, Con carga de vna missa. Cada dia de los quales se an de dar q[uen]ta por averlos Recibido d[ic]ha señora Avadesa

Al margen izquierdo: el nicho de D. Lazaro

Al margen derecho: $6.600 \mathrm{~d}$ [ucado]s

$$
22.000 \mathrm{~d} \text { [ucado]s }
$$

XIII) ASMC, Libro de Cuentas 3, fol. 190v: capellanía de Lázaro Díaz del Valle en Santa María de Carbajal de León, s. f.

mas Daendatta. Cinq[uen]ta ducados que dio a el Liz[encia]do manuel peres capella[n] De don Lazaro que es lo que inportta La capellania cada año $Y$ queda pagado, asta el dia de ss[a]n Marcos de settentta Ytres $=Y$ se adviertte queda deuiendo el conventto. Cinq[uen]ta ducados al capellan $\mathrm{a}[\mathrm{n}]$ ttecedentte $=$ aldeoy ques natural de ss[a]n miguel de el v[all]e =

\section{Al margen: Capellan de D. Lazaro}

XIV) AHPM, Prot. 9470, Esno. Juan de Siles Calahorra, fols. 747r-747v: Francisco Lobera cobra de Juan Díaz Rodero 22000 reales para darlos al Convento de Santa María de Carbajal de León para la memoria de Lázaro Díaz del Valle y el traslado de sus huesos, 7 de junio de $1670^{51}$.

En la villa de Madrid a siete dias del mes de Junio de mill y seis[cient]os y setenta años ante mi el ss[criba]no pu[bli]co y testigos parecio fran[cis]co Lobera Vecino desta Villa y testamentario de Don Lazaro Diez del Valle y de la Puerta Coronista $\mathrm{q}[\mathrm{ue}]$ fue de su M[a]g[esta]d ya difunto $=\mathrm{Y}$ confeso auer reciuido de Juan Diaz Rodero Mercader de sedas de su M[a]g[esta]d como testamentario del d[ic]ho Don Lazaro Diez del Valle Veinte y dos mill Reales de V[ell]on que le a entregado para efecto de que el $d[i c]$ ho otorgante los de y entregue a el combento de Relixiosas de san Benito que llaman de carbaxal para la memoria que el $\mathrm{d}$ [ic]ho Don Lazaro por su testamento debaxo de cuya disposicion fallecio fundo en el d[ic]ho combento el qual a de otorgar los despachos necesarios para el cumplim[ien]to de la $\mathrm{d}[\mathrm{ic}]$ ha memoria para cuyo esfecto y lleuar los guesos del d[ic]ho Don Lazaro a la d[ic]ha ciu[da]d y poner el epitafçio y quadros que se dispone por el $\mathrm{d}[\mathrm{ic}]$ ho testamento el $\mathrm{d}$ [ic] ho otorgante ha a la d[ic]ha ciu[da]d de Leon De los quales $\mathrm{d}[\mathrm{ic}]$ hos Veinte y dos mill Reales de Vellon se dio por contento y entregado a toda su Voluntad por auerlos reciuido en Vna letra dada en esta corte oy dia de la f[ec]ha por Don Joseph Alfonso de Valladolid Cañedo sobre Antonio Bermudez v[e]z[in]o de la $\mathrm{d}$ [ic]ha ciu[da]d de Leon a fauor del d[ic]ho otorgante por reciuidos del $\mathrm{d}[\mathrm{ic}]$ ho Juan Diaz renuncia las leyes de la entrega prueua della y demas del caso y otorga reciuo y carta de pago a fauor del $\mathrm{d}[\mathrm{ic}] \mathrm{ho}$

\footnotetext{
${ }^{51}$ Los restos de Díaz del Valle fueron llevados a León entre el 7 de junio de 1670 y el 14 de agosto del mismo año, pues en esa fecha Francisco Lobera, testamentario y encargado del traslado, ya estaba de vuelta en Madrid cobrando los emolumentos de su trabajo (doc. XV).
} 
Juan diaz tam bastante y firme como a su $\mathrm{d}[\mathrm{e}] \mathrm{r}[\mathrm{ech}] \mathrm{o}$ combenga siendo testigos Andres Merino Joseph Bidarte y Juan Sanchez residentes en esta corte e yo el scriuano que doy fe e conozco a el otorgante q[ue] lo firmo $=$

francisco lobera

$\mathrm{A}[\mathrm{n}]$ te $\mathrm{mi}$

Juan de Siles [rubricado]

XV) AHPM, Prot. 9471, Esno. Juan de Siles Calahorra, fols. 207r-207v: Francisco Lobera recibe 2200 reales de Juan Díaz Rodero y José Hidalgo por el traslado a León de los huesos de Lázaro Díaz del Valle y la disposición de su epitafio, 14 de agosto de 1670.

En la Villa de Madrid a Catorze dias del mes de Agosto de mill y seisçientos y setenta años ante mi el escribano pp[ubli]co y testigos parezio fran[cis]co Lobera Vezino desta Villa testamentario de Don lazaro Díez del Valle ya difunto Coronista que fue de su Mag[esta]d = Y comfesso hauer reziuido, de Juan Diaz Rodero y Joseph Hidalgo como testamentarios del d[ic]ho Don lazaro Dos mill y Ducientos Reales de Vellon por los mismos que los d[ic]hos Juan Diaz Rodero y Joseph Hidalgo acordaron se diessen de los v[iene]s de la d[ic]ha testamentaria a el $\mathrm{d}$ [ic]ho fran[cis]co lovera otorg[an]te en considerazion de la ocupacion y trabajo que tubo en la d[ic]ha testamentaria y en ir a la ciu[da]d de Leon a lleber los Huessos del d[ic]ho Don Lazaro y dispones en $\mathrm{d}$ [ic]ha ciu[da]d el que se pussiesse en el combento de relixiossas de ella que llaman de Caruajal el ePitafio y quadros que para $\mathrm{d}[\mathrm{ic}]$ ho efecto dispusso el $\mathrm{d}[\mathrm{ic}]$ ho Don lazaro $=$ De los quales $\mathrm{d}[\mathrm{ic}] \mathrm{hos}$ Dos mill y doçientos Reales de V[ell]on se dio por contento y entregado a toda su boluntad con renunciacion de las Leies de la entrega prueba della y demas del casso y dellos dio y otorgo carta de pago en fauor de los d[ic]hos Ju[an] Diaz Rodero y Josseph Hidalgo tan bastante y firme como a su derecho Combenga siendo testigos Diego Mande Alarcon fran[cis]co de pinedo y $\mathrm{Ju}$ [an] Sanchez ressidentes en esta corte e yo el ss[criba]no que doi fee conozco al otorg[an]te q[ue] lo firmo =

francisco Lobera

$\mathrm{A}[\mathrm{n}] \mathrm{te} \mathrm{mi}$

Juan de Siles [rubricado]

XVI) AHPM, Prot. 11431, Esno. José García Remón, fols. 420r-430v: "fundacion de Memorias la testamentaria de $\mathrm{D}[\mathrm{o}] \mathrm{n}$ Lazaro Diaz del Valle=en el Rector del Ospital de la buena dicha". Fundaciones pías en la institución madrileña citada, mediante cláusula testamentaria, por Lázaro Díaz del Valle, 19 de agosto de $1670^{*}$.

Sea notorio a los que la presente escrip[tu]ra de fundacion de Memoria de misas Doctacion de Capellanía Patronatto de legos y situacion de su renta Vieren como yo Juan Díaz Rodero. Mercader de sedas francisco Lobera y Joseph ydalgo. Vecinos desta uilla de Madrid testamentarios ynsolidum de Don lazaro Diaz del Valle y de la Puerta Criado de su Mag[esta]d en su

\footnotetext{
${ }^{*}$ El Hospital de la Buena Dicha, fundado en 1594 y hoy perdido, se conoció durante mucho tiempo como Hospital de la Concepción de Nuestra Señora, y después como Nuestra Señora de la Buena Dicha. Era el hospital de la parroquia de San Martín, a cuya colación pertenecía la calle Silva, donde murió Díaz del Valle (vid. doc. V). La advocación la explica Jerónimo de Quintana: “(...) Dedicaro[n]le a la Co[n]cepcion de N. Señora, cuya imagen se venera en el con inuocacion de la Buena-dicha, $q[\mathrm{ue}]$ dizen la dio vn sieruo de Dios (...)"; vid. "A LA MVY ANTIGUA / NOBLE Y CORONADA / VILLA DE MADRID. / HISTORIA / DE SV ANTIGVEDAD, / NOBLEZA Y GRANDEZA. / POR EL LICENCIADO GERONIMO D[E] QVINTANA / Clerigo Presbitero, Notario del Santo Oficio de la / Inquisicion, Rector del Hospital de la / Latina, y natural de la misma Villa. / CON PRIVILEGIO EN MADRID EN LA IMPRENTA DEL REYNO. / AÑO M.DC.XXIX [1629]", Libro tercero, Capitulo CXVII, fol. 450, col. 1.
} 
R[ea]l Capilla su coronistta General destos Reynos ynstituydos por tales en el testamento debajo cuya disposicion murio Otorgado ante Juan de siles ss[criba]no de su Magestad en Veinte y seis de febrero del año pasado de mill y s[ei]s[cient]os y sesenta y nueue que para mayor fuerza desta Escriptura pedimos al ymfraescripto ss[criba]no del numero aquí le ynserte e incorpore y lo hice asi que su thenor a la letra sacado bien y fielmente es como sigue

\section{Aquí El testamento}

Y Vsando de la d[ic]ha testamentaria que tenemos hazeptada $Y$ de nuevo hazeptamos. Para lo aquí Contenido Decimos que comformandonos con la Voluntad del d[ic]ho Don lacaro Diaz del Valle Y clausulas de su testamento y hauer Ynsituydo A su alma Por heredera Dejando a nuestra eleccion la distribucion del Remanente que quedase de sus Vienes despues de Cumplida su dispusiçion y mediante hauernos comunicado la mucha debocion y cariño que siempre auia tenido a la s[an]ta Ymagen de n[uest]ra s[eñor]a de la buena $d[i c]$ ha y su ospital que esta en esta corte y que se fundasse Vna memoria de Vna misa cada semana que se dijesse en el Perpetuamente por su alma y las de penas del purgatorio nombrando Por patron y capellan desta memoria al Rector que es o fuesse del para que siempre fuese permanente y no faltase el cuidado de que se dixese d[ic]ha missa cada semana y porque de lo procedido del d[ic]ho Remanente Para en poder del $\mathrm{d}[\mathrm{ic}]$ ho Joseph ydalgo seis mill ducientos y quarenta Reales de Vellon con los quales y sus rreditos de ellos. que montan a Racon de Veinte mill el millar Trecientos y doce Reales cada año tenemos resuelto y ajustado de fundar la d[ic]ha memoria Patronato de legos y poniendolo en effecto considerando ser hacertada esta Resolucion y que quanto antes se baya diciendo $\mathrm{d}[\mathrm{ic}]$ ha missa cada semana y se ympongan azensso en parte fixa y segura $\mathrm{d}[\mathrm{ic}] \mathrm{hos}$ seis mill $\mathrm{du}$ - cientos y quarenta Reales a n[uest]ra satisfacion y eleccion y del d[ic]ho Rector que al presente es y que lo que de al que le sube e diere despues de sus dias = Otorgamos y conocemos Por esta presente Cartta y en la mejor M[aner]a y forma que aya lugar de derecho Y mas queda y deua Ualer funDamos Doctamos y situamos Para siempre Per Petuamento la d[ic]ha Memoria y patronatto de legos en la forma y con las calidades clausulas requisitos y condiciones que siguen

Primeramente Ponemos señalamos y situamos por Vienes y rrenta fixa desta memoria y Patronato de legos desde ahora para quando sube e da el casso de que este fixa y segura que a de ser Por el dia de Nauidad que Vendra deste presente año de mill y s[ei]s[cient]os y setenta los $\mathrm{d}[\mathrm{ic}] \mathrm{hos}$ seis mill ducientos y quarenta R[eale]s de Vellon y Por ellos los trecientos y doze Reales de sus rreditos al año el qual d[ic]ho principal y rreditos an de estar siempre permanentes sujetos y obligados a la $\mathrm{d}[\mathrm{ic}]$ ha memoria y patronato y de $\mathrm{d}[\mathrm{ic}] \mathrm{hos}$ Reditos de poder Gocar y goce en propiedad y posesion desde el dia de su fundacion en adelante el $\mathrm{d}[\mathrm{ic}] \mathrm{ho}$ Rector que al presente es o fuere del d[ic]ho Ospital de n[uest]ra s[eñor]a de la buena d[ic]ha desta corte Como patron y capellan que an de ser de d[ic]ha memoria cada uno en su tiempo para siempre Perpetuamente

Yten Comformandonos con la Voluntad del d[ic]ho Don Lazaro Diaz del Valle y Para que con toda puntualidad se diga $\mathrm{d}$ [ic]ha missa. Cada semana sin que en ello aya genero de omision Nombramos desde luego Portal Patron y Capellan desta memoria y Patronatto que la diga a el maestro D Andres de Zieza Villa Real Rector que al presente es de d[ic]ho Ospital y a todos los demas que lo fueren despues de sus dias los quales es condicion formal deste fundaz[i]on que cada vno en su tiempo Perpetuamente a y an de tener obligacion de 
decir y hacer se diga la d[ic]ha misa Cada semana Por el alma del d[ic]ho Do lazaro y por las de penas del purgatorio en el Altar de n[uest]ra s[eñor]a de la buena d[ic]ha del d[ic]ho Ospital en uno de los dias de cada semana el que eligieren que no a de pasar ninguna sin que se diga y si por enfermedad o otra ocupacion se dejare decir aya de tener obligacion $\mathrm{d}[\mathrm{ic}] \mathrm{ho}$ Rector de dar la limosna de ella a sacerdote que la diga y si fuere Por bacante asta que aya nuebo Rector El que entrare aya de tener obligacion asi mismo de tomar quenta de las que se an $\mathrm{d}[\mathrm{ic}]$ ho y de las que faltaren de decir hazer que se digan a costa de la renta y si estubiere cobrada A costa de los Vienes del Rector que falleciere de manera que nunca falte de decirse d[ic]ha misa. Cada semana sobre todo lo qual se les encarga conciencia

Yten para que se conozca y este siempre permanente esta memoria y patronato ponemos condiz[i]on de que se aya de asentar y Preuenir en las tablas de memorias y libros del d[ic]ho Ospital o en la parte donde se deua anotar y preuenir Para que en todo t[iem]po conste y no benga en oluido y para que el s[eño]r Visit[ad]or Eclesiastico que es o fuere desta d[ic]ha m[emori]a de Madrid y su partido pida quenta de su cumplim[ien]to sin que en ninguna manera tengamos facultad ni adquirir Por esta Racon mas conocimiento que el de sauer si se cumple $O$ no se cumple. Y el tal Rector que es o fuere tal Patron y capellan de la d[ic]ha memoria no a de poder pedir en ningun tiempo Reducion ni minoracion de las mismas que ban señaladas que an de ser cinq[uen]ta y dos cada año con presupuesto de decir se le siguen gastos en la cobranza de la rrenta de ellas ni por esterilidad ni otra causa respecto de Hauerse ajustado con d[ic]ho M[aest]ro D Andres de Zieza rector que al presente es de $\mathrm{d}[\mathrm{ic}] \mathrm{ho}$ Ospital asi para el como los demas que le sucediesen fuese la limosna de seis Reales por cada missa que azen los trecientos y doze que le uan señalados de Renta Y ser muy competente Para su estauilidad y permanencia y en casso que algunos de los $\mathrm{d}[\mathrm{ic}]$ hos Rectores que subcedieren no azepten esta memoria a de quedar por patron de ella d[ic]ho Ospital y la persona por cuya quenta Corriere su gouierno para Prouerle y hazer que se digan las d[ic]has misas segun queda dispuesto y con las calidades desta fundaz[i]on sin alterarla en cosa alguna -

Yten que por quanto esta memoria se funda e ynstituye de Vienes meramente temporales a de ser perPetuamente secular y lega de Patronato de legos y no sujeta A colacion ni canonica ynstituzion $Y$ en que su Santidad ni prelado alguno eclesiastico superior ni ymferior ni rregular ni se an de entrometer en proberla ni conferirla sino que no solo Hauer subcedido en ella luego que le toque $Y$ llegue a noticia del Patron y Capellan que le tocare que an de ser el Rector que fuere de $\mathrm{d}[\mathrm{ic}]$ ho Ospital $\mathrm{Y}$ en casso de no hacetarla lo sea El mesmo Ospital o persona Por cuya quenta Corra su gouierno an de Poder thomar Posesion de ella $\mathrm{Y}$ su rrenta Cumplirla y gocarla $=\mathrm{Y}$ por la misma racon no se a de pagar de d[ic]ha Renta subsidio escusado ni otro ningun Ympuesto que aya ni pueda auer y en casso de estar Vaca d[ic]ha memoria aunque Passe qualquier termino que aya $\mathrm{Y}$ tarde en entrarla a goçar el patron y Capellan a q[uie]n tocare Por la falta que ubiere siempre toca a d[ic]ho Rector y no haceptandola a d[ic]ho Ospital y personas por cuya quenta corra su gouierno Para que la cumpla $Y$ aga Cumplir y entre a cobrar su rrenta y Por esta Racon y Las demas que por d[e]r[ech]o deuemos hallamos para Lo que a esto toca se a uistto no adquerir derecho alguno el hordinario Respecto de que el adquerirlo solo prozede en Veneficios eclesiasticos y Capellanias Colatiuas. Y no enmem[darl]as como esta que lo hazemos meramente de V[ien]es temporales - 
Ytten que rrespecto de que los $\mathrm{d}[\mathrm{ic}]$ hos seis mill Ducientos y quarenta Reales de V[ell]on de principal de que se compone El caudal desta memoria con los trecientos Y dos Reales de Renta que de ellos an de proceder estan por Ymponer $\mathrm{Y}$ subrrogar en parte fixa y segura donde se cobreen y precisamente se an de subrrogar E Ynponer Para el dia de Nauidad deste presente año de mill y s[eiscient]os y setenta Es condiz[i]on que desde d[ic]ho dia en adelante o por lo menos desde primero de Henero del año que bendra de mill y s[eiscient]os y setenta y uno en adelante del $\mathrm{d}[\mathrm{ic}]$ ho Rector que al presente es y los que le subcedieren An de terner obligaz[i]on de decir $\mathrm{d}[\mathrm{ic}$ ]has misas $\mathrm{Y}$ an de entrar a cobrar la r[en]ta de ellas en dos pagas Por mitad San Juan y Nauidad de cada Vn año y si antes subcediere el Aberse ympuesto y subrrogado $\mathrm{d}[\mathrm{ic}]$ ha cantidad desde entonces se an de enpecar a decir $\mathrm{d}[\mathrm{ic}]$ has misas $\mathrm{y}$ a cobrar sus rentas segun los placos que estubieren señalados en la fundacion que se a de hacer de $\mathrm{d}[\mathrm{ic}]$ ha Rentta $=\mathrm{y}$ siempre que llegare el casso de rredimirse y quitarse los d[ic]hos seis mill ducientos y quarenta $\mathrm{R}$ [eale]s de V[ell]on se an de depositar en persona lega llana y abonada que de ellos de quenta A satisfacion del d[ic]ho Patron y de la Justicia hordinaria desta uilla con cuya ynteruenz[i]on y ymformaz[i]on de Vtilidad de $\mathrm{d}[\mathrm{ic}$ ]ha mem[ori]a se an de Voluer a Ymponer y subrrogar sin que $\mathrm{d}[\mathrm{ic}] \mathrm{ho}$ Principal entre en poder del d[ic]ho Patron y Capellan por que sola le a de tocar la acion de perceuir sus rreditos y subrrogarse el principal con su Ynteruenz[i]on y satisfacion $=\mathrm{Y}$ desde luego $\mathrm{p}[\mathrm{ar}] \mathrm{a}$ siempre Perpetuamente $Y$ para que en todo $t[i e m]$ po sea firme y estable esta fundacion que no se pueda consumir Pro y al mes la enajenaz[i]on Venta o yPoteca Permuta o otro qualq[uie]r Genero y esPecie de enajenaz[i]on de los $\mathrm{d}[\mathrm{ic}]$ hos seis mill duçientos y quarenta reales de principal lo qual se a de cumplir guardar y ex[ecut]ar siempre que subceda El redimirse y quitarse la d[ic]ha Cantidad -

Con las quales $\mathrm{d}[\mathrm{ic}]$ has condiziones Preuenciones y calidades de susso Contenidas $\mathrm{Y}$ las demas que por $\mathrm{d}[\mathrm{e}] \mathrm{r}[\mathrm{ech}] \mathrm{o}$ sean necesarias Para su mayor Perpetuidad y firmeza hazemos esta $d[i c]$ ha fundacion de mem[ori]a Patronato de legos a cuya segur[ida]d obligamos los $\mathrm{d}[\mathrm{ic}]$ hos seis mill Ducientos y quarenta R[eale]s de principal y sus reditos que les corresponden a Racon de a V[ein]te mill El millar Comforme la Ympuss[ici]on que dellos se a de hacer y Por tal caudal suyo Propio lo a de tener gocar y poseer El d[ic]ho Patron y capellan que de ella es y a lo adelante fuere y para su cobranza Damos a cada uno en su tiempo Poder y facultad Cumplida sin ning[u]na limitacion y cesion en caussa Propia Para que cada Vno por si solo Pueda Hauer Reciuir y cobrar los d[ic]hos Reditos y dar de ellos la carta o cartas de pago que sean necesarias y al tiempo de que se redima d[ic]ho Principal otorguen Asimismo Las escrituras de Redencion Y liberacion que sean necesarias con las fuerças y clausulas que comuengan para todo lo qual $Y$ su anejo y dependiente y Para parecer en Juicio y hacer los autos y dilixencias que sean menester los hacemos procuradores Actores en $\mathrm{su} \mathrm{f}[\mathrm{ec}]$ ho y caso propio sin que para todo lo suso $\mathrm{d}[\mathrm{ic}]$ ho sea necesario mas recaudo que testimonio desta clausula con la qual Damos fin a esta fundacion y Patronato que a de ser firme para siempre perpetuamente y guardarse y cumplirse las condiciones y Grauamenes con que ua echa sin que falte cosa alguna $\mathrm{Y}$ por los que a nosotros toca nos obligamos a que siempre sera firme $y$ Valedera en todo tiempo segun por derecho deuemos ser obligados $=$

\section{Al margen: Aceptaz[i]on}

Y El d[ic]ho Maestro D[o]n Andres de Zeeza y Villa R[ea]l que estaua presente a todo lo de suso contenido y auiendolo 
oydo y entendido = Dixo que haceptaua y aceptto esta escriptura y por lo que a el toca y tocar puede se obligo en forma segun deue ser obligado de guardar y cumplir las calidades condiziones Preuenciones y Grauamenes Con que esta echa por los $\mathrm{d}[\mathrm{ic}]$ hos testament[a]rios sin alterarla en cosa alguna Y miestrar Viuiere desde El dia de Nauidad que uendra deste Presente año o desde primero de henero del de mill y s[ei]s[cient]os Y sesenta y uno en adelantte dira la $d[i c]$ ha missa Cada semana sin que en ninguna manera pase ninguna sin decirla y en casso de enfermedad V otra ocupacion la hara decir dando la limosna a otro sacerdote que la diga y si antes de Nauidad se ympusiere Arrenta El principal de que se Compone la de esta Capellania Comencara a decir las $\mathrm{d}[\mathrm{ic}]$ has misas Vno y otro segun $\mathrm{y}$ en la forma que diere principio. La cobranza de ellas y esta Haceptacion Haze por si mesmo y en nombre de los demas Rectores Patrones y Capellanes que por tiempo fueren y le ssubcedieren en la forma que ba Preuenido en esta fundacion y en aquella uia y forma que Puede y de derecho aya lugar obliga al d[ic]ho Patron y Capellan que lo fuere en adelante subcesiuamente Vnos a otros a que cumpliran con lo dispuestto Preuenido y ordenado en $\mathrm{d}[\mathrm{ic}] \mathrm{ha}$ fundacion sin faltar ni alterarla en cosa alguna Para cuyo Cumplimiento lo Reciue Por sentencia definitiua de Juez competente Pasa en autoridad de cossa juzgada con sumision que hizo en forma a los Justicias y Juezes que de sus Causas puedan Y deuan conozer y especialmente se sometio a la de sus Juezes y prelados desta uilla de Madrid y su partido Renuncio ttodas las Leyes fueros y derechos de su fayor con la General en forma y el capitulo $\mathrm{O}$ duar dus de solucionitus $=\mathrm{y}$ todas las $\mathrm{d}[\mathrm{ic}]$ has partes cada una Por lo que le toca la Otorgaron Assí Ante mi El presente ss[criba]no en la uilla de Madrid A Diez y nuebe Dias del mes de Agosto de mill y s[ei]s[cient]os y setenta años siendo testigos Bar[tolo]me ffe[rnande]z sotelo ss[criba]no de su Mag[esta]d Vidal Garcia y Padro Marguello Redondo Residentes en esta corte y los Otorgantes que yo El escriuano Doy fe conozco lo firmaron $=$ Sobre Raido $=\mathrm{y}$ nuebe $=$ lla Real

M[aest]ro Don Andres de cieza y Vi-

$$
\begin{aligned}
& \text { francisco lobera } \\
& \text { Ju[an] diaz Rodero } \\
& \text { Joseph Hidalgo }
\end{aligned}
$$

Ante mi

Joseph Gar[ci]a Remon [rubricado]

[Sigue a continuación un traslado del testamento de Lázaro Díaz del Valle otorgado ante el escribano real Juan de Siles Calahorra; vid. supra, Apéndice Documental, doc. IV].

XVII) AHDM, Sección Fundaciones, 1/910-3 Díaz del Valle y de la Puerta, Lázaro: nota del Rector del Hospital de la Buena Dicha en referencia a la Fundación de Memoria de Misas... de Lázaro Díaz del Valle, s.f.

D[o]n Joseph de Mondragon Presu[iter]o Rector del hospital de N[uest]ra s[eño]ra de la Buena dicha y como tal capellan y cumplidor de la Mem[ori]a q en d[ic]ho hosp[ita]l fundo D[o]n lazaro Diaz del Valle $=$ Digo q[ue] a d[ic]ha mem[ori]a pertenece un r[edi]to de 6240 R[eale]s de pr[incip]al contra D[o]n Joseph Doblado y otros consortes quienes $\mathrm{p}[\mathrm{o}] \mathrm{r}$ escrip[tu]ra q[ue] otorgaron de reconocim[ien]tto pagan sus reditos, $\mathrm{Y}$ respectto de parar en este tribun[a]l d[ic]ha escrip[tu]ra de Reconocim[ien]to orig[ina]l con otros autos de $\mathrm{d}$ [ic]ha mem[ori]a y q[ue] esta deue parar en mi poder como tal cumplidor $\mathrm{p}[\mathrm{o}] \mathrm{r}$ ttanto $=$ 
A Vm sup[li]co Se sirua mandar q[ue] quedando copia en los $\mathrm{d}$ [ic]hos autos de d[ic]ha escrip[tur]a de Reconocim[ien]to se me Entregue la orig[ina]l para los efectos q[ue] me combenga pido Justt[ici]a \&a =

D Joseph Mondragon [rubricado]

Al margen: dio R[eci]uo de la ss[critu]ra de reconocimiento en el Libro de vissita.

[El mismo legajo contiene un traslado completo de la memoria de fundación que hemos transcrito en el documento anterior, adjuntándose esta nota del Rector].

XVIII) AHPM, Prot. 9478, Esno. Juan de Siles Calahorra, fols. 185r-185v: Juan Díaz Rodero cobra 30000 mrs. de gajes de Lázaro Díaz del Valle, por disposición testamentaria, 9 de febrero de 1674 .

En la Villa de Madrid a Nuebe dias del mes de febrero de mill y seis[cient]os y setenta y quatro años ante mi el, ss[criba]no publico y testigos parecio Juan Diaz Rodero Mercader de Sedas de su Magestad y Vecino de esta Villa como testamentario insolidum que es de Don Lazaro Diaz del Valle ya difunto como consta de los recados de legitimacion que tiene presentados antes de ahora $=\mathrm{Y}$ confesso haber recibido de Juan Perez de Zumelzu thessorero de la Capilla Real de su Mag[esta]d treinta mill Maravedis de Vellon que en el Rol de Gages de la $\mathrm{d}[\mathrm{ic}] \mathrm{ha}$ Real Capilla de el tercio segundo del año pasado de mill y seis[cient]os y setenta y tres su f[ec]ha a Diez de Henero de este presente de mill y seis[cient]os y setenta y quatro se libra[r]on en el d[ic]ho Juan Perez de Zumelzu a la Parte de el d[ic]ho Don Lazaro Diaz de el Valle por quenta de lo que se le quedo debiendo, asta fin del año de mill y seis[cient]os y cinquenta y tres como parece por d[ic]ho Rol a que se remite $=$ De los quales $\mathrm{d}[\mathrm{ic}]$ hos treinta mill Marabedis de Vellon se dio por contento y entregado a toda su Voluntad con re- nunciacion de las leyes de la entrega prueba de ella y de mas de el casso y de ellos como tal testamentario dio y otorgo carta de pago en fabor de el d[ic]ho Juan Perez de Zumel$\mathrm{zu}$ tan bastante y firme como a su $\mathrm{d}[\mathrm{e}] \mathrm{r}[\mathrm{ech}] \mathrm{o}$ combenga siendo testigos Martin Perez de Riba de Neira fran[cis]co de Arberas y Juan Sanchez residentes en esta corte e yo el ss[criba]no que doy fe e conozco a el otorg[an]te que lo firmo =

$$
\text { Ju[an] Diaz Rodero }
$$

Ante mi

Juan de Siles [rubricado]

XIX) AHPM, Prot. 9478, Esno. Juan de Siles Calahorra, fols. 190r-190v: Juan Díaz Rodero cobra 21000 mrs. de gajes de Lázaro Díaz del Valle, por disposición testamentaria, 9 de febrero de 1674 .

En la Villa de Madrid a Nuebe días de el mes de febrero de mill y seis[cient]os y setenta y quatro años ante $\mathrm{mi}$ el ss[criba]no publico y testigos parecio Juan Diaz Rodero Mercader de Sedas de su Mag[esta]d y Vecino de esta Villa de Madrid como testamentario insolidum que es de de Don Lazaro Díaz del Valle ya difunto como consta de los recados de legitimacion que tiene entregados antes de ahora $=\mathrm{Y}$ confesso haber recibido de Juan Perez de Zumelzu Thesorero de la Capilla Real de su Mag[esta]d Veinte y Vn mill Marabedis de Vellon que en la lista de Distribuciones; de la dicha Real capilla del tercio segundo del año pasado, de mill y seis[cient]os y setenta y quatro es su f[ec]ha a Diez de Henero de este presente año de mill y seis[cient]os y setenta y quatro, se libraron en el d[ic]ho Juan Perez de Zumelzu a la parte de el d[ic]ho Don Lazaro Diaz del Valle por quenta de lo que se le quedo debiendo asta fin de el año de mill y seis[cient]os y cinquanta y tres como parece por dicha lista a que se remite $=$ De los quales dichos Veinte y Vn mill Marabedis de Vellon el d[ic]ho 
otorg[an]se te dio por contento y entregado a toda su Voluntad con renunciacion de las Leyes de la Entrega prueba de ella y demas de el casso y de ellos como tal testamentario dio y otorgo carta de pago en fabor de el d[ic]ho Juan Perez de Zumelzu tan bastante y firme como a su derecho combenga siendo testigos Martin Perez de Riba deneira fran[cis]co de Arberas y Juan Sanchez residentes en esta corte e yo el ss[criba]no que doy fe e conozco a el otorgante que lo firmo $=$

\section{Ju[an] Diaz Rodero}

Ante mi

Juan de Siles [rubricado] 


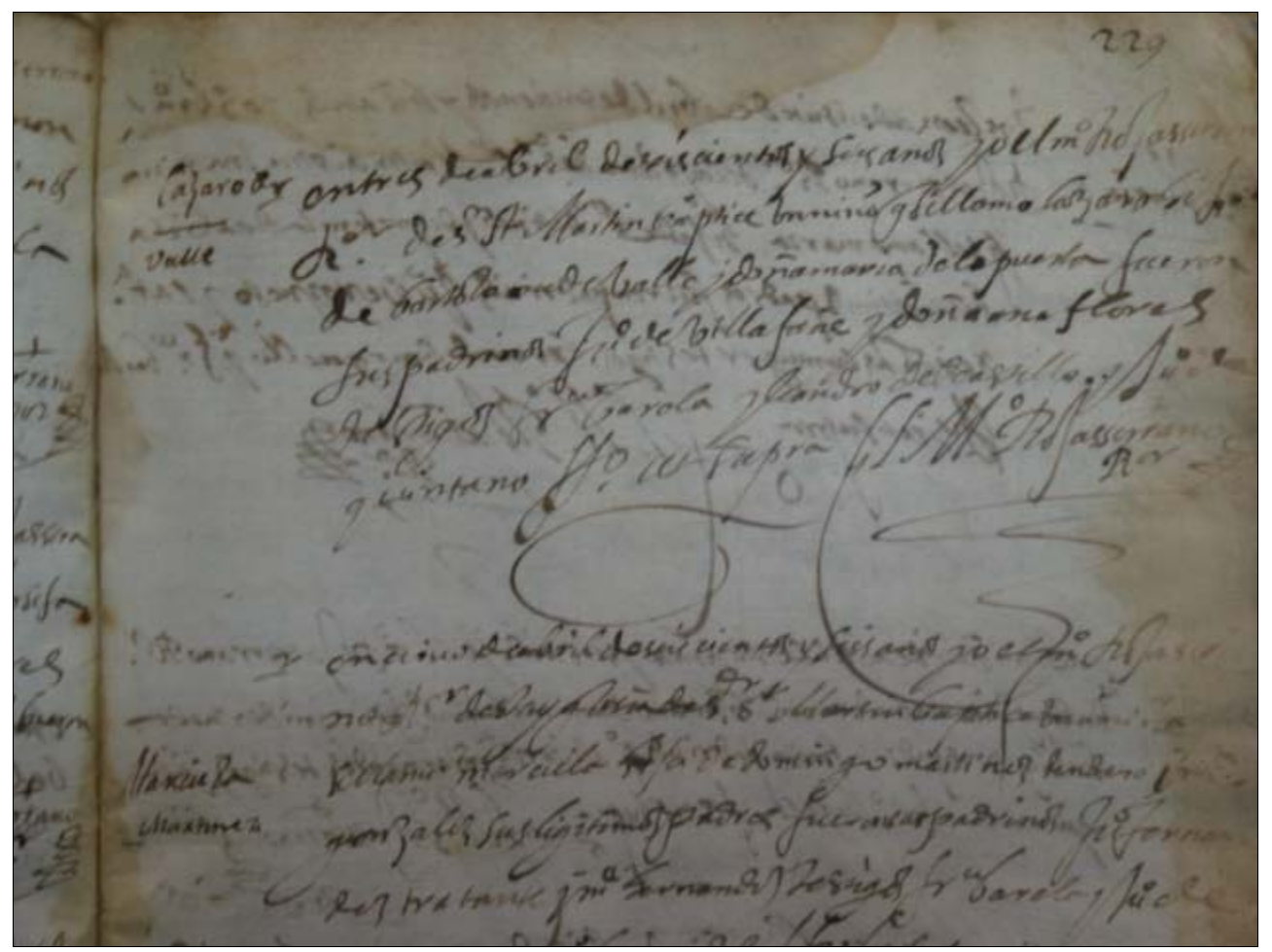

- Fig. 1. Partida de bautismo de Lázaro Díaz del Valle, 3 de abril de 1606. Archivo parroquial de San Martín (León). Libro $2^{0}$ de Bautizos, fol. 229.

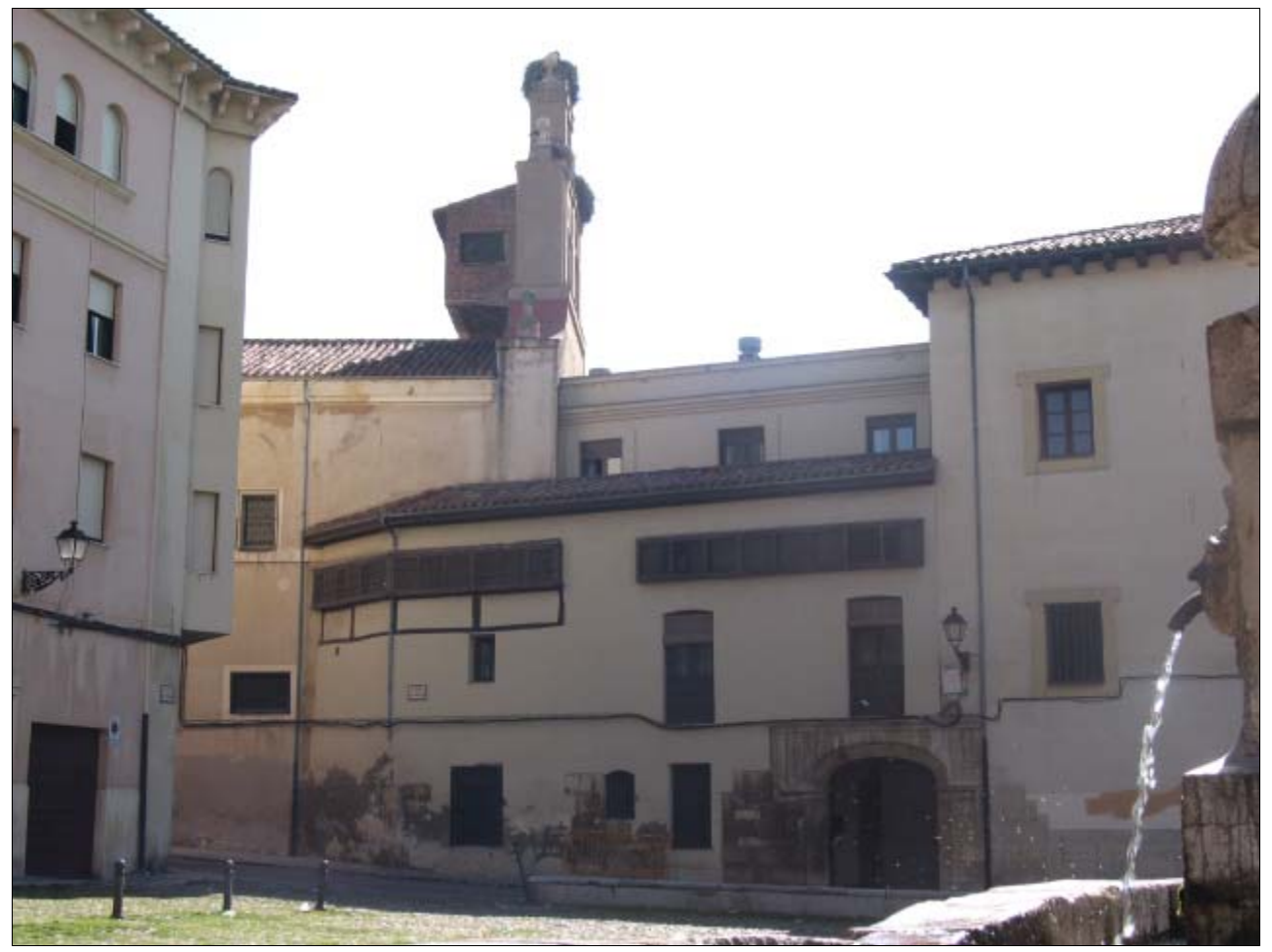

- Fig. 2. Convento de Santa María de Carbajal (León). 


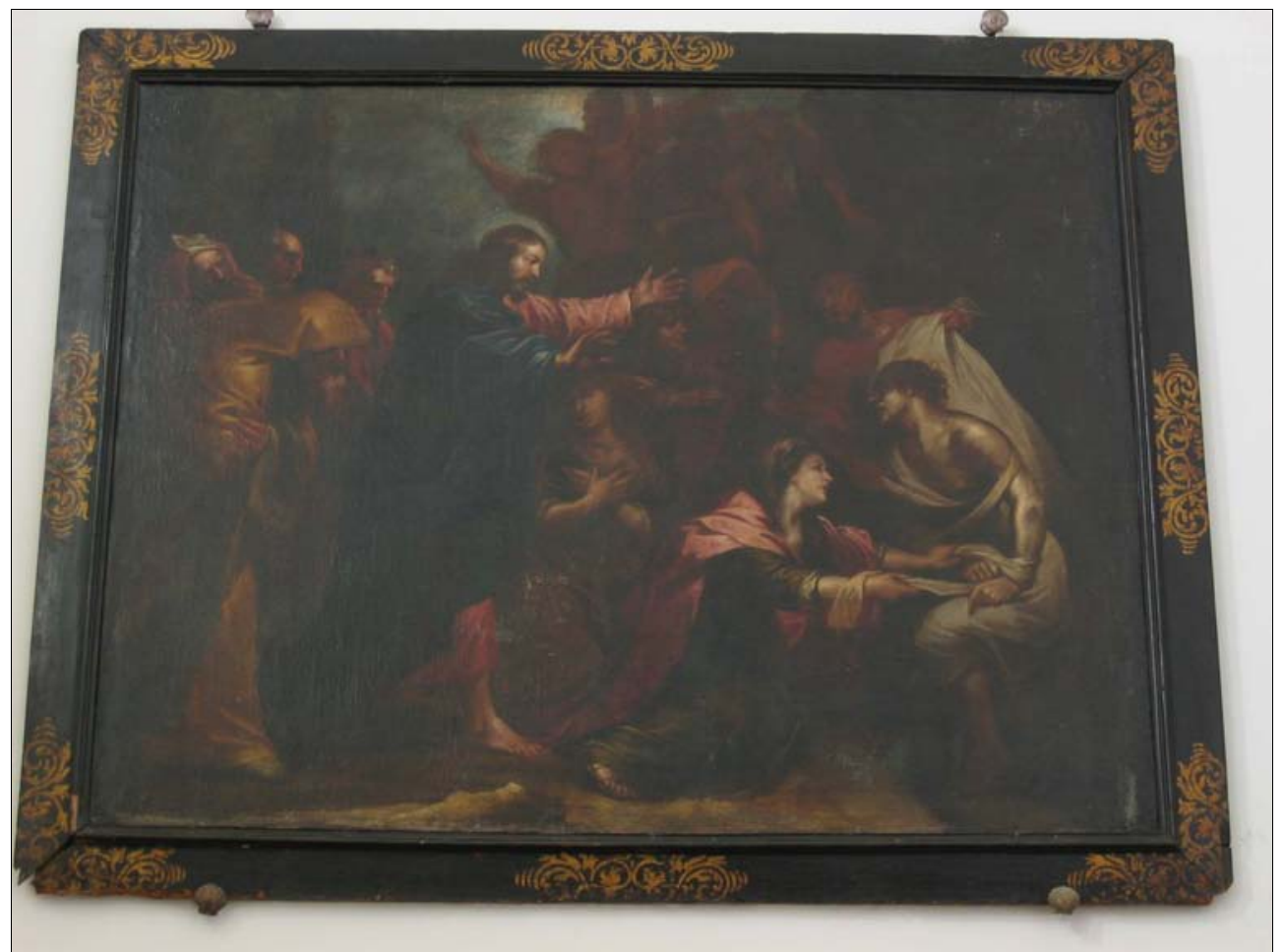

- Fig. 3. Juan Antonio Escalante, Resurrección de Lázaro, c. 1669. Convento de Santa María de Carbajal.

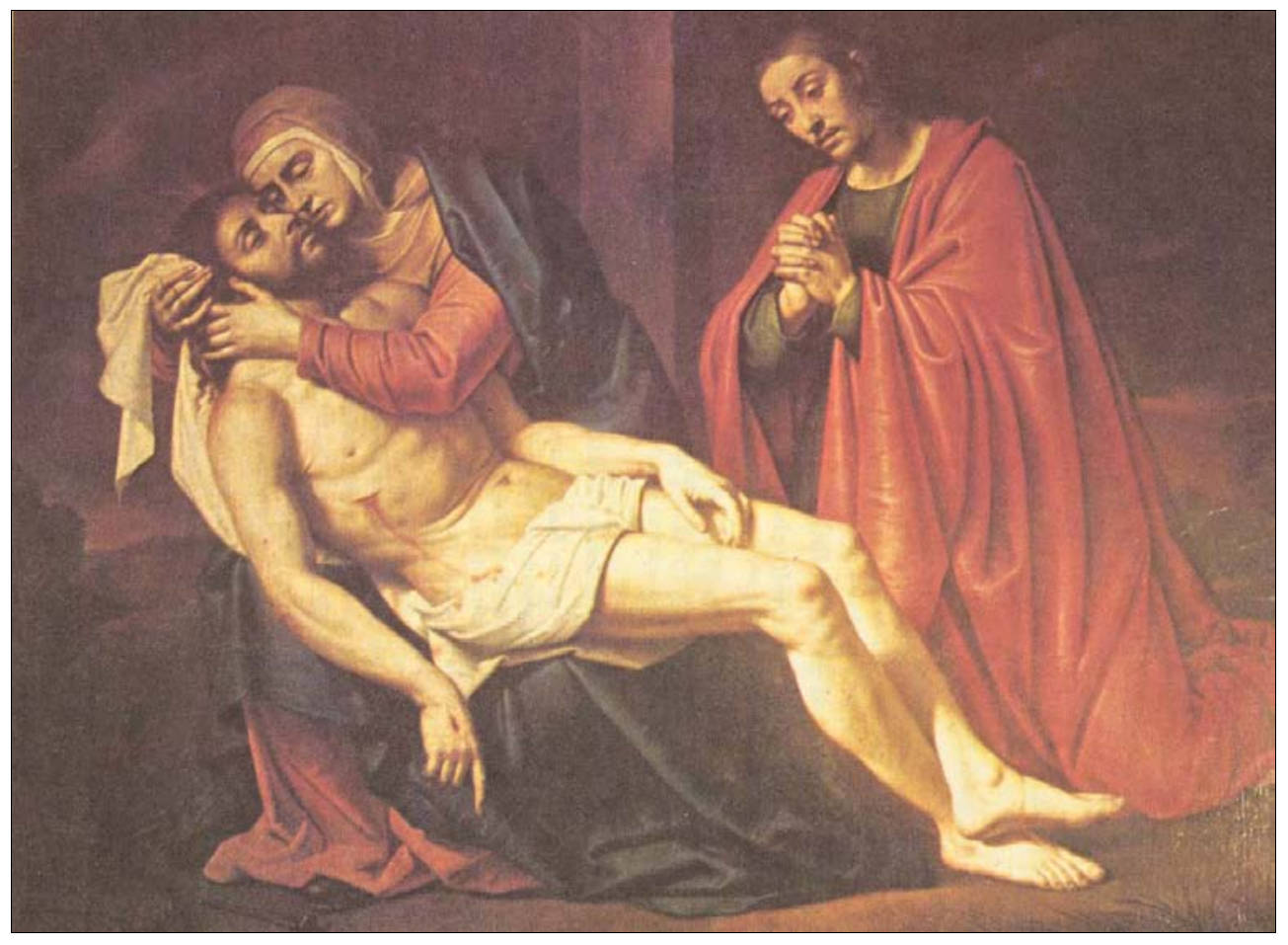

- Fig. 4. Antonio Arias, Piedad, 1658. Convento de Santa María de Carbajal. 